\title{
Marketplace or Reseller?
}

\section{Citation}

Hagiu, Andrei, and Julian Wright. "Marketplace or Reseller?" Management Science (forthcoming).

\section{Published Version}

http://dx.doi.org/10.1287/mnsc.2014.2042

\section{Permanent link}

http://nrs.harvard.edu/urn-3:HUL.InstRepos:14358172

\section{Terms of Use}

This article was downloaded from Harvard University's DASH repository, and is made available under the terms and conditions applicable to Open Access Policy Articles, as set forth at http:// nrs.harvard.edu/urn-3:HUL.InstRepos:dash.current.terms-of-use\#OAP

\section{Share Your Story}

The Harvard community has made this article openly available.

Please share how this access benefits you. Submit a story.

Accessibility 
H A R VAR D

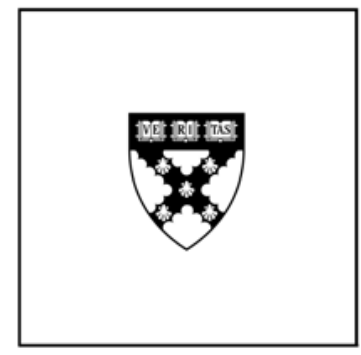

\title{
Marketplace or reseller?
}

\author{
Andrei Hagiu \\ Julian Wright
}

\section{Working Paper}

13-092

January 31, 2014 


\title{
Marketplace or reseller?*
}

\author{
Andrei Hagiu ${ }^{\dagger}$ and Julian Wright ${ }^{\ddagger}$
}

January 2014

\begin{abstract}
Intermediaries can choose between functioning as a marketplace (on which suppliers sell their products directly to buyers) or as a reseller (purchasing products from suppliers and selling them to buyers). We model this as a decision between whether control rights over a non-contractible decision variable (the choice of some marketing activity) are better held by suppliers (the marketplacemode) or by the intermediary (the reseller-mode). Whether the marketplace or the reseller mode is preferred depends on whether independent suppliers or the intermediary have more important information relevant to the optimal tailoring of marketing activities for each specific product. We show that this tradeoff is shifted towards the reseller-mode when marketing activities create spillovers across products and when network effects lead to unfavorable expectations about supplier participation. If the reseller has a variable cost advantage (respectively, disadvantage) relative to the marketplace then the tradeoff is shifted towards the marketplace for long-tail (respectively, shorttail) products. We thus provide a theory of which products an intermediary should offer in each mode. We also provide some empirical evidence that supports our main results.
\end{abstract}

JEL classification: D4, L1, L5

Keywords: Intermediation, multi-sided platforms, control rights, marketing.

${ }^{*}$ We thank Jim Dana, Josh Lerner, Chris Nosko, Martin Peitz, Steve Tadelis, Eric Van den Steen and seminar audiences at Berkeley Haas School of Business, Bocconi University, ESMT, Harvard Business School, INSEAD, LMU, MIT, the University of Chicago, the University of Mannheim and the University of Würzburg for their very helpful comments. Y.V. Kiran and Ziqiu Ye provided excellent research assistance.

${ }^{\dagger}$ Harvard Business School. E-mail: ahagiu@hbs.edu

${ }^{\ddagger}$ Department of Economics. National University of Singapore. E-mail: jwright@nus.edu.sg 


\section{Introduction}

Retailers like 7-Eleven, Eastbay.com, Lowes and Zappos.com act as intermediaries by reselling the products they purchase from suppliers to buyers. Other intermediaries, such as Alibaba.com, eBay.com, Premium Outlets, and Simon Malls act as marketplaces, in which suppliers sell directly to buyers via a platform. In the existing literature, the intermediation model — reseller or marketplace — is taken as given. It is important to recognize, however, that intermediaries can often choose under which mode to operate.

For example, most electronics retailers function as resellers. They take ownership and control over products from branded suppliers and choose how to sell them in their stores (layout, pricing, promotions, emphasis, etc.). Recently, however, the largest such retailer in the United States, Best Buy, has taken a step towards the marketplace mode by allowing Apple, Samsung and Microsoft to launch their own mini-stores within Best Buy stores (Apple in 2011, Microsoft and Samsung in 2013). These brands control the product layout in these mini-stores, staff them with their own product specialists and Samsung even offers its own checkout service. ${ }^{1}$ Similarly, Buy.com was founded in 1997 as a pure online reseller, but starting in 2006 it aggressively expanded its marketplace offering. By 2010, when it was acquired by Rakuten, Japan's largest online shopping mall, Buy.com was a hybrid, with sales roughly evenly distributed between the reseller and the marketplace modes. ${ }^{2}$ In 2013 , it was rebranded Rakuten.com Shopping and was reportedly moving towards a $100 \%$ marketplace mode. ${ }^{3}$ An example of a transition in the opposite direction is provided by Zappos.com, the leading online shoe retailer in the U.S., which started off in 1999 as a marketplace, before turning itself into a pure reseller by the mid-2000s, prior to its 2009 acquisition by Amazon. Other examples where intermediaries make such choices include: department stores (resellers for some product categories and marketplaces for others, most notably cosmetics, where branded suppliers control independent counters); Amazon.com (started off as a pure reseller but now operates as a marketplace as well); digital content intermediaries (e.g. Comcast, DirecTV, Apple's iTunes and Netflix operate as resellers, whereas Apple's iPhone App Store and Google Play operate mostly as marketplaces).

This paper analyzes the choice facing an intermediary between operating as a marketplace, as a reseller, or as a hybrid, having some products offered under each of the two different modes. What are the trade-offs that drive an intermediary to adopt one mode over the other, or both? We present

\footnotetext{
${ }^{1}$ See "Best Buy to Carve Out Microsoft Mini-Stores," by Shira Ovide and Ann Zimmerman, 13 June 2013, The Wall Street Journal; "Samsung Sets Up Boutique in Best Buy; Electronics Retailer Will Have Dedicated Boutique for When Galaxy S4 Debuts," by Ann Zimmerman, 4 April 2013, The Wall Street Journal.

${ }^{2}$ Geoffrey A. Fowler and Daisuke Wakabayashi "Japan's Rakuten to Acquire Buy.com," Wall Street Journal, 21 May 2010.

${ }^{3}$ http://dealnews.com/features/Buy.com-to-Become-a-Marketplace-only-Site-Hopes-to-Take-onAmazon/661313.html
} 
a formal model for analyzing some of the fundamental tradeoffs that arise in comparing resellers with marketplaces, and determining which products to offer under each mode.

We take the view that a fundamental distinction between marketplaces and resellers is the allocation of control rights between independent suppliers and the intermediary over non-contractible decisions (prices, advertising, customer service, responsibility for order fulfillment, etc.) pertaining to the products being sold. In the case of a pure marketplace, all of these residual control rights rest with independent suppliers. In the case of a pure reseller, all residual control rights rest with the intermediary (i.e. the reseller).

In our model, we focus on a single, non-contractible decision variable, which can be interpreted as the choice of some marketing activity that occurs through this particular intermediary and that is undertaken by the party holding residual control rights (i.e. the reseller, or each independent supplier in the case of a marketplace). Examples of such an activity include the way in which a product is displayed, or the extent to which its brand is promoted relative to its features (e.g. through in-store signage or sales staff). The intermediary and the suppliers each have private information about the ideal choice of the marketing activity. Drivers of the optimal intermediation mode that we analyze include the relative importance of the suppliers' versus the intermediary's private information, the presence of spillovers across products generated by marketing activities, whether products are longtail or short-tail, and a possible chicken-and-egg problem faced by the marketplace when suppliers hold unfavorable expectations about other suppliers' participation on the marketplace. We also establish conditions under which a hybrid mode is optimal and characterize its optimal design in such cases. Our article thus offers a guide to how intermediaries should optimally position themselves between the two different modes. Finally, we offer some empirical evidence that corroborates our model's predictions.

\subsection{Literature review}

The marketplaces we study are a type of multi-sided platform (or two-sided market). Multi-sided platforms are organizations that get two or more sides on board and enable direct interactions between them. In the case of marketplaces, the two sides are buyers and sellers, and the interaction is the commercial trade between them. Thus, our framework does not fit all types of multi-sided platforms. For instance, when the two sides are not trading a "product" that can be purchased and resold, the choice to become a reseller does not arise (e.g. a nightclub). Nevertheless, marketplaces are an important subclass of multi-sided platforms.

Our contribution to the literature on multi-sided platforms departs from the seminal models in the two-sided market literature (e.g. Armstrong 2006, Caillaud and Jullien 2003, Parker and Van Alstyne 2005, Rochet and Tirole 2003) by focusing on the role of non-contractible decisions and whether the 
intermediary or the third-party suppliers have control rights over these decisions - a novelty in this literature. An important corollary of our modelling is that the specification of residual control rights helps distinguish multi-sided platforms from resellers. Specifically, residual control rights remain with sellers in the case of multi-sided platforms. The existing literature on two-sided markets has struggled with this issue. According to some existing definitions, grocery stores are examples of multi-sided platforms even though many economists think they are not (e.g. Rochet and Tirole 2006, and Rysman 2009). At the same time, we extend the existing literature by considering multi-sidedness as a choice rather than as a given characteristic of industries or firms. Thus, our work is related to recent efforts to expand the formal study of strategic decisions made by platforms beyond pricing (see, for example, Nocke et al. 2007, Gawer and Henderson 2007, Gawer and Cusumano 2008, Boudreau 2010, Eisenmann et al. 2011, Hagiu and Jullien 2011, Parker and Van Alstyne 2012, Gawer and Phillips 2013).

The importance of the strategic choice between marketplaces and resellers, and some of the tradeoffs that can arise are discussed in Hagiu (2007) and Hagiu and Wright (2011, 2013). This paper formalizes a framework in which the allocation of residual control rights creates meaningful distinctions between the two modes, and emphasizes fundamental tradeoffs that were not raised in these earlier works. Note that our focus is on control rights and not on the specific mechanisms through which a marketplace or a reseller reduce buyer and seller search and transaction costs (such as in, Bakos, 1997). The distinction between the marketplace and reseller modes of intermediation is also present in Hagiu and Lee (2011). Their set-up features two downstream intermediaries who first compete for the affiliation of one upstream supplier and then compete for customers (buyers). However, in their analysis the mode of intermediation (marketplace or reseller) for the two downstream firms is exogenously given. The focus of their analysis is the effect of intermediation model on the likelihood that the upstream supplier deals exclusively with one intermediary as opposed to both.

By equating the difference between marketplaces and resellers to the allocation of residual control rights between independent suppliers and the intermediary, our work is loosely related to the voluminous literature on vertical integration and the theory of the firm (see, for example, Grossman and Hart 1986, Hart and Moore 1990 and Williamson 1975). However, rather than studying "make or buy "decisions, we study "enable or resell "decisions, which involve quite a different economic analysis. The key difference is the following. In the "make or buy" (vertical integration) decision, regardless of the choice, the focal firm contracts with and controls the sale to buyers. By contrast, in the "marketplace or re-seller "decision, the marketplace mode involves contractual relationships between buyers and suppliers, to which the focal firm (intermediary) is not a party - it is merely an enabler of those contractual relationships. Consequently, the specific tradeoffs are different. In particular, consider contractual incompleteness. When complete contracts are infeasible, vertical integration (equivalent 
to the allocation of residual control rights) is driven by the need to minimize hold-up risk by (or of) some suppliers, because hold-up risk tends to lead to sub-optimal relationship-specific investments (Grossman and Hart 1986). This issue is not very relevant for the "marketplace or re-seller "decision since the hold-up by (or of) a supplier remains a risk whether the intermediary is a marketplace or a reseller. Conversely, the contractual incompleteness in our model relates to non-contractible actions which must be made contingent on information that is revealed after the intermediary contracts with suppliers and before the products are sold to buyers. This issue has little if any relevance to "make or buy "decisions.

More closely related to our paper is a literature on organizational design which explores whether centralized or decentralized decision-making is better. At a high level, we share with this literature the focus on non-contractible decisions (ex-ante and ex-post) and on the tradeoffs that arise from allocating the relevant decision rights to different parties. Loosely speaking, centralization corresponds to our reseller mode and decentralization corresponds to our marketplace mode. See, for example, Alonso et al. (2008, 2013), although their focus on strategic communication (their 2008 paper) and the tradeoff between information breadth and depth (in their 2013 paper) is very different from ours.

Finally, our work relates to the recent work by Gans (2012), Foros et al. (2013) and Johnson (2013a and b) that analyzes the agency model (suppliers set prices and share revenues with downstream retailers) and contrasts it with the traditional wholesale model (suppliers set wholesale prices and retailers set retail prices). These articles explore the implications of specific contract forms that have recently emerged in the selling of digital content (e.g. application stores and e-books). Our article complements this emerging literature given that contract forms are largely neutral in our analysis we instead focus on the role of private information and non-contractible decisions.

\section{Model set-up}

There are $N>1$ independent suppliers. Each supplier $i=1, \ldots, N$ has a unique product. The marginal cost of supplying each product (i.e. the opportunity cost to suppliers of providing the product for sale) is normalized to zero without loss of generality. To sell the products to buyers, suppliers must go through a monopoly intermediary.

Initially, in our model all products (and all suppliers) are treated symmetrically. This allows us to show the trade-offs we are interested in most clearly when focusing on the choice between a pure reseller $(R)$ and a pure marketplace $(M)$. The role of asymmetries across products is discussed in Section 4, where such asymmetries provide a natural explanation of why intermediaries may prefer a hybrid mode. 


\subsection{Demand structure}

There is a continuum of many identical buyers. Each buyer is willing to pay $v$ for each product she is interested in, where $v$ is commonly known. In order to access the products, buyers must affiliate with (i.e. join) the intermediary, which we assume is costless.

We assume that the number of buyers for product $i$ is

$$
m-\left(a_{i}-a_{i}^{*}\right)^{2},
$$

where $a_{i}$ is the choice of marketing activities made by the owner of product $i$ (supplier $i$ or the reseller), and where

$$
a_{i}^{*}=\theta+\gamma_{i}+\delta_{i}
$$

is the ideal choice of marketing activity for product $i$. We have in mind activities that take place at or over the intermediary and that help attract (and convert) buyers.

We assume $\theta$ is commonly known. The term $\gamma_{i}$ is an i.i.d. random variable, whose realization is private information known to the intermediary at the time it chooses its marketing activities. Similarly, the term $\delta_{i}$ is an i.i.d. random variable, whose realization is private information known to supplier $i$ at the time the supplier chooses its marketing activities. The random variables $\gamma_{i}$ and $\delta_{i}$ are drawn independently for all $i$, and they have expected values equal to zero and variances denoted $V_{\gamma}$ and $V_{\delta}$, respectively.

The key assumption is that marketing activities $a_{i}$ are non-contractible: this may be because they encompass unobservable actions or are too costly to fully specify in a contract. Still, an intermediary or supplier that was fully informed of $\gamma_{i}$ and $\delta_{i}$ would be able to choose the ideal marketing activity for product $i$ and thereby achieve the highest level of demand possible (i.e. $m$ ). We therefore also assume that the private information contained in $\gamma_{i}$ and $\delta_{i}$ is prohibitively hard to communicate to the other party in a cost-effective manner. Absent full information, neither suppliers nor the intermediary can expect to make the ideal choice of marketing activities. The extent to which the owner of product $i$ (supplier $i$ or the reseller) is expected to be less effective depends on the variance of the component of $a_{i}^{*}$ that it does not observe. Thus, the relative importance of the intermediary's versus the suppliers' local information is captured by the comparison between $V_{\gamma}$ and $V_{\delta}$.

Our formulation of marketing activities above is best interpreted as representing a "horizontal choice". A given product can be marketed in multiple ways, all at the same cost, which we normalize to zero. For example, suppose there is a fixed amount of promotion that can be done for each TV product at Best Buy: the amount may be restricted by the available signage space or by the limited 
amount of time that sales staff have to discuss products with potential buyers. That fixed promotion capacity can be allocated among two activities: emphasizing the specific brand of the TV set vs. emphasizing specific product features (e.g. high-definition or smart TV functionality). One can then interpret $a_{i}$ as the relative amounts of promotion capacity allocated to brand emphasis and promotion capacity allocated to emphasis of product features. If $a_{i}$ is below the ideal level $a_{i}^{*}$ then further emphasizing brand at the expense of product features will attract more buyers to product $i$, and conversely if $a_{i}$ is above the ideal level $a_{i}^{*}{ }^{4}$

More generally, one can think of $a_{i}$ as encompassing dimensions of how shelf space or stores (physical or virtual) are laid out. Suppliers and the reseller may have different information about the best way to make such lay-out decisions. Different lay-out arrangements have similar costs, so these can be considered horizontal decisions. For instance, one dimension along which suppliers and the reseller might have different information on is the extent to which demand is maximized by putting the same brand's products close together versus putting complementary products (of different brands) close together.

Needless to say, there are other ways to formulate how marketing activities affect demand. For our purposes there are two critical modeling ingredients: (i) the marketing choice is influenced by the private information embodied in $a_{i}^{*}$ and (ii) the optimal choice $a_{i}^{*}$ is well defined due to diminishing returns to marketing. In Section 5.1 we provide an alternative modelling formulation in which $a_{i}$ can be interpreted as the level of investment in marketing, so a higher $a_{i}$ always increases demand, with the marginal effectiveness proportional to $a_{i}^{*}$. By assuming quadratic marketing costs, we show that the baseline tradeoffs in Section 3 below remain the same.

\subsection{Cost structure}

If the intermediary is a marketplace, each individual supplier incurs a fixed cost, denoted $F_{M}>0$, which is the cost of setting up the capability of selling on the marketplace. Each supplier also incurs a constant transaction cost of selling each unit of its product, equal to $f_{M}$. If the intermediary is a reseller, it incurs a fixed cost $F_{R}>0$ for each product it offers (e.g. the costs of quality control, inventory capacity, contractual arrangements, etc). $R$ 's transaction cost of selling each unit of a product is equal to $f_{R}$. We add the natural assumption that $v>f_{k}$ for $k \in\{M, R\}$. We also assume that the profit from each product is positive regardless of whether it is offered under the $R$-mode or the $M$-mode. Equations (4) and (8) in Section 3 below show that a sufficient condition to ensure this property is:

$$
\left(v-f_{k}\right)\left[m-\max \left(V_{\delta}, V_{\gamma}\right)\right]>F_{k},
$$

\footnotetext{
${ }^{4}$ We are grateful to an anonymous referee for pointing out this interpretation of our model.
} 
for $k \in\{M, R\}$.

Initially, we assume that $f \equiv f_{M}=f_{R}$ and $F \equiv F_{M}=F_{R}$, so that the cost structure of supplying $n$ products is the same under the two different modes of intermediation. This assumption will be relaxed in Section 3.2 where we focus on cost differences that can affect the choice between the two modes. We normalize the fixed costs of setting up an intermediary (i.e. before it sells any products) to zero, regardless of its mode.

\subsection{Pricing instruments and control rights}

If the intermediary chooses the $R$-mode, it makes a take-it-or-leave-it contract offer to $n \leq N$ suppliers. The offer consists of the price $R$ will pay for each unit it buys, in exchange for which $R$ obtains the control rights over marketing and pricing to buyers. $R$ then chooses marketing activities and prices offered to buyers for all products whose suppliers have accepted the contract offer. As will be noted below, the pricing choice is trivial in our model, so only control over marketing choices matters. Whenever it makes a sale to buyers, $R$ pays the contract price to the corresponding supplier.

If the intermediary chooses the $M$-mode, its take-it-or-leave-it contract offer to $n \leq N$ suppliers consists simply of a fixed participation fee $P$ that each supplier must pay in order to join. In our benchmark setting, restricting $M$ to a participation fee is without loss of generality: it would not do any better if it were able to observe supplier sales and charge variable fees. Where there is a role for variable fees, this will be explicitly noted and analyzed. Participating suppliers maintain control over marketing activities and pricing to buyers, to whom they sell directly. In particular, there is no access fee to buyers. As will become clear below, this assumption is immaterial since in our benchmark model, buyers are left with zero surplus.

Consistent with our distinction between marketplaces and resellers, we assume only one party $(R$ or the corresponding supplier $i$ ) has control rights over marketing activities for a given product $i$ that affect consumer demand through this particular intermediary. This does not rule out that suppliers may also choose marketing activities through other channels than the intermediary, but these are assumed to work independently of the activities we are studying, so we abstract from them.

The reason we have chosen marketing activities as the focal decision variable is two-fold. First, in many real-world contexts, prices are set by contracts between suppliers and intermediaries (e.g. through resale price-maintenance agreements). In such contexts, pricing decisions do not create any meaningful economic distinctions between marketplaces and resellers. In contrast, marketing activities are much less likely to be contractible. For instance, it would be very hard for Sony to enforce specific ways in which Best Buy sales people are supposed to talk about Sony products to customers. The only realistic way Sony could do this would be to have its own sales people in Best Buy stores — a situation 
which is captured by the marketplace mode in our model. Second, from a modelling perspective, it turns out that working with marketing activities is quite tractable and allows us to explore a broad range of tradeoffs. For completeness, in Section 5.5 we consider a version of our model with prices as the non-contractible decision variables and show that our main findings continue to hold.

\subsection{Timing}

The timing we assume throughout is as follows:

\begin{tabular}{l|l}
\hline \multicolumn{2}{l}{ Stage 0. Intermediary chooses mode - Reseller or Marketplace } \\
\hline Reseller & Marketplace \\
\hline $\begin{array}{l}\text { Stage 1. Reseller makes take-it-or-leave-it offer to } \\
\text { suppliers; suppliers decide whether or not to accept. }\end{array}$ & $\begin{array}{l}\text { Stage 1. Marketplace sets the fixed participation fee } \\
\text { participate. }\end{array}$ \\
$\begin{array}{l}\text { Stage 2. Reseller learns } \gamma_{i} \text { for each product and } \\
\text { chooses marketing activities and prices to buyers for } \\
\text { all products it has acquired. }\end{array}$ & $\begin{array}{l}\text { Stage 2. Each supplier learns its } \delta_{i} \text { and chooses the } \\
\text { corresponding marketing activity and price to buy- }\end{array}$ \\
ers. \\
Stage 3. Buyers make purchase decisions.
\end{tabular}

These particular timing assumptions are not critical to our analysis. The important assumption is that parties should learn their private information prior to making their decisions about marketing activities. We denote by $E_{R}\left[\right.$ [.] the expectation taken by $R$ and by $E_{i}$ [.] the expectation taken by supplier $i$ after they learn their private information. We denote by $E$ [.] the expectations taken by either party prior to learning their private information.

Some straightforward implications follow from our timing assumption. First, in all cases, the owner of each product $i$ (supplier $i$ or $R$ ) charges buyers a price equal to $v$, which extracts the entire buyer surplus. Indeed, an informed buyer that wishes to purchase product $i$ does so whenever her opportunity cost of going to the intermediary (zero by assumption) plus the price charged for the product is less than or equal to her willingness-to-pay $v$. This allows us to focus on the key tradeoffs between the two modes without introducing any pricing distortions on the buyer side. Since pricing does not depend on local information in any way, it does not produce any meaningful difference between the two modes of intermediation in our model. Thus, whether prices can be contracted or not is irrelevant in our setting. Instead, all the action is concentrated in the choices of marketing activities. Second, the intermediary has all the bargaining power. It therefore extracts the entire expected surplus from all participating 
suppliers. ${ }^{5}$ As a result, in the benchmark model, total intermediary profit and total expected surplus (or welfare) are the same. This changes in Section 3.3, where $M$ suffers from unfavorable supplier expectations.

\section{Key tradeoffs}

This section presents the analysis and results for the benchmark setting outlined in the previous section, in the case of an intermediary choosing between the $R$-mode and the $M$-mode. We then introduce the possibility of spillovers, cost differences and network effects to highlight other important tradeoffs between the two modes.

Reseller R's optimal contract offer to suppliers is to buy each unit at a price of zero — suppliers accept since it meets their opportunity cost, which we have normalized to zero. Suppose $R$ makes the offer to $n \leq N$ suppliers, so that it can sell $n$ products to buyers. $R$ then decides on $a_{1}, \ldots, a_{n}$ to maximize its expected profit from selling the different products.

The reseller sets $a_{1}, \ldots, a_{n}$ together to maximize expected joint profit after observing $\gamma_{1}, \ldots, \gamma_{n}$, but without observing $\delta_{1}, \ldots, \delta_{n}$. The reseller's expected profit at stage 2 can be written as

$$
\Pi_{R}(n)=(v-f) \sum_{i=1}^{n} E_{R}\left[m-\left(a_{i}-\left(\theta+\gamma_{i}+\delta_{i}\right)\right)^{2}\right]-n F .
$$

Using that $E_{R}\left(\delta_{i}\right)=0$ and taking first order conditions, we obtain the optimal choice of marketing activities for each product

$$
a_{i}^{R}=\theta+\gamma_{i}
$$

Substituting (3) into (2) and taking expectations, the reseller's expected profit of selling each product is

$$
(v-f)\left(m-V_{\delta}\right)-F .
$$

Given (1), this is positive, so the reseller offers all $N$ products to obtain the expected profit

$$
\Pi_{R}=N\left((v-f)\left(m-V_{\delta}\right)-F\right) .
$$

\footnotetext{
${ }^{5}$ Our main results do not depend on these simplifying features of the model. In particular, we show that they continue to hold both when suppliers have positive bargaining power (see Section 5.2) and when buyers have bargaining power (see Section 5.4).
} 
Marketplace In this mode, suppliers maintain control rights over their marketing decisions $a_{i}$. Supplier $i$ 's expected profit net of the participation fee $P$, evaluated at stage 2 , is

$$
\pi_{i}=(v-f) E_{i}\left[m-\left(a_{i}-\left(\theta+\gamma_{i}+\delta_{i}\right)\right)^{2}\right]-F-P
$$

where supplier $i$ observes its own $\delta_{i}$ after joining the platform (but not any $\gamma_{i}$ or any other $\delta_{j}$ ). Using that $E_{i}\left(\gamma_{i}\right)=0$ and taking first order conditions, we obtain the optimal choice of marketing activities for each product

$$
a_{i}^{M}=\theta+\delta_{i}
$$

Substituting (7) into (6) and taking expectations, supplier $i$ 's expected profit from participating with $M$ is

$$
\pi_{i}=(v-f)\left(m-V_{\gamma}\right)-F-P .
$$

$M$ can set $P=(v-f)\left(m-V_{\gamma}\right)-F$ per supplier, which is positive given (1). It will therefore want to attract all $N$ suppliers to obtain an expected profit of

$$
\Pi_{M}=N\left((v-f)\left(m-V_{\gamma}\right)-F\right)
$$

Comparing (5) with (9), we obtain the following benchmark result

Proposition 1 The $M$-mode is preferred to the $R$-mode if and only if the variance of the suppliers' local information exceeds the variance of the intermediary's local information, i.e. if and only if $V_{\delta} \geq V_{\gamma}$.

The condition above provides a simple benchmark to evaluate reseller-versus-marketplace tradeoffs. Control should be given to the party whose information is more important in terms of how best to design marketing activities. Note this comparison does not depend on the assumption that $m, \theta$, or $F$ are the same for each product. The result would be identical if these varied across products in some way which was equally observed by suppliers and the intermediary. Our result also does not depend on $M$ being assumed to charge only a fixed participation fee. If $M$ could observe sales and also set a variable fee per unit of sales, this would reduce the supplier's margin from each sale, but not the choice of marketing activities. As a result, the effect would be to just transfer profits from the supplier to $M$, as with the participation fee.

In Proposition 1 we implicitly assumed that the intermediary has to choose the same mode for all of its products. This assumption is without loss of generality in this benchmark setting, given the informational advantage (whichever direction it is in) is consistent across products. An intermediary 
that offers some products directly itself (i.e. in the $R$-mode) and allows independent suppliers to sell other products over its platform (i.e. in the $M$-mode) would do strictly worse whenever $V_{\delta} \neq V_{\gamma}$. We explore settings in which such a hybrid mode would be chosen in Section 4 .

\subsection{Cross-product spillovers}

In many real-world settings, marketing activities have cross-product spillovers. This naturally occurs when the different products belong to the same product category. To reflect this in the simplest possible way, suppose higher levels of the marketing choice for one product either increase or decrease the number of buyers for all other products. Assuming spillovers take a linear form, demand for product $i$ becomes

$$
m-\left(a_{i}-a_{i}^{*}\right)^{2}+x \sum_{j \neq i} a_{j}
$$

where $x$ is the magnitude of the spillovers.

We allow $x$ to be either negative or positive in order to accommodate different interpretations. For instance, recall our interpretation of marketing activities $a_{i}$ as horizontal choices and consider our previous example of Best Buy and TV sets (see Section 2.1). In this example, allocating a larger amount of signage space to the brand of a particular TV relative to its product features may decrease demand for other products by crowding out consumer attention for other brands, or by reducing the positive spillover that would be created by promoting the common product features (e.g. smart TV functionality). Similarly, in the example of store lay-out, locating products of the same brands close together rather than the complementary products of different brands would reduce the positive spillovers across complementary products of different brands.

$R$ 's profit at stage 2 if it sells $n$ products is

$$
\Pi_{R}(n)=\max _{a_{1}, a_{2}, . ., a_{n}}\left\{(v-f) \sum_{i=1}^{n} E_{R}\left[m-\left(a_{i}-a_{i}^{*}\right)^{2}+x \sum_{j \neq i} a_{j}\right]-n F\right\} .
$$

Compared to before, $R$ adjusts its marketing activities for product $i$ to take into account the externality on the $(n-1)$ other products, so

$$
a_{i}^{R}=\theta+\gamma_{i}+\frac{x}{2}(n-1)
$$

Substituting $a_{i}^{R}$ back into profits, the reseller's expected profit from selling $n$ products is

$$
\Pi_{R}(n)=(v-f) \sum_{i=1}^{n}\left(m-V_{\delta}+x \theta(n-1)+x \sum_{j \neq i} \gamma_{j}+\frac{x^{2}(n-1)^{2}}{4}\right)-n F .
$$


Therefore, at stage 1 , the expected profit of a reseller selling $n$ products is

$$
E\left[\Pi_{R}(n)\right]=n\left((v-f)\left(m-V_{\delta}+x \theta(n-1)+\frac{x^{2}(n-1)^{2}}{4}\right)-F\right)
$$

If $x<0$ then assumption (1) is no longer sufficient to ensure intermediaries prefer to operate with all $N$ products. We assume instead

$$
(v-f)\left(m-\max \left(V_{\delta}, V_{\gamma}\right)+x \theta(N-1)\right)>F,
$$

which requires that $x$ cannot be too negative. Under this assumption, $R$ will want to offer all $N$ products and obtains expected profit

$$
\Pi_{R}=N\left((v-f)\left(m-V_{\delta}+x \theta(N-1)+\frac{x^{2}(N-1)^{2}}{4}\right)-F\right) .
$$

In contrast, an individual supplier selling over $M$ obtains expected profit of

$$
\pi_{i}=(v-f) E_{i}\left[m-\left(a_{i}-a_{i}^{*}\right)^{2}+x \sum_{j \neq i} a_{j}\right]-F
$$

so it ignores the effect of its choice of marketing activities on other suppliers. The result of profit maximization is $a_{i}^{M}=\theta+\delta_{i}$, as before, and so the expected profit for a given supplier deciding whether or not to participate at stage 1 is

$$
\pi_{i}=(v-f)\left(m-V_{\gamma}+x \theta(n-1)\right)-F .
$$

Note that an individual supplier's profit depends on how many other suppliers join, through the term $x \theta(n-1)$. When $x>0$ this feature can give rise to multiple equilibria for given participation fees, where more suppliers join if they expect others to join. To address this potential multiplicity of equilibria, we assume here that suppliers hold favorable expectations, meaning suppliers always coordinate on an equilibrium in which all of them join if doing so gives them non-negative profits in the resulting equilibrium. ${ }^{6}$ Again, (10) ensures $M$ can extract a positive fee from each supplier, and so $M$ will offer all $N$ products even if $x<0$, and obtain an expected profit of

$$
\Pi_{M}=N\left((v-f)\left(m-V_{\gamma}+x \theta(N-1)\right)-F\right) .
$$

\footnotetext{
${ }^{6}$ The case in which suppliers hold unfavorable expectations is analyzed in Section 3.3. See footnote 7 there.
} 
Comparing (11) and (12) we obtain:

Proposition 2 The $M$-mode is preferred to the $R$-mode if and only if $V_{\delta} \geq V_{\gamma}+\frac{x^{2}(N-1)^{2}}{4}$.

Introducing spillovers unambiguously shifts the tradeoff in favor of the $R$-mode. Thus, the $R$-mode may now be preferred even if $V_{\delta}>V_{\gamma}$. This reflects that $R$ takes into account the cross-product externalities from the promotion of product $i$ on other products, something $M$ cannot do if suppliers cannot coordinate their decisions and $M$ cannot condition on suppliers' choices of marketing activity. As a result, the $M$-mode is preferred whenever suppliers' informational advantage in exploiting local information more than offsets the importance of accounting for externalities. Note that the sign of the externality $x$ (i.e. whether spillovers are positive or negative) does not matter in this case - all that matters is its magnitude. Also note that variable fees remain redundant since they do not influence an individual supplier's choice of marketing activities.

\subsection{Cost differences}

In this section we focus on the effect of cost differences between $R$ and $M$. Recall in the benchmark setting we assumed $F_{R}=F_{M}$ and $f_{R}=f_{M}$. Consider relaxing these equalities. Equations (5) and (9) become

$$
\begin{aligned}
\Pi_{R} & =N\left(\left(v-f_{R}\right)\left(m-V_{\delta}\right)-F_{R}\right) \\
\Pi_{M} & =N\left(\left(v-f_{M}\right)\left(m-V_{\gamma}\right)-F_{M}\right) .
\end{aligned}
$$

Given (1) both expressions are positive. We obtain:

Proposition 3 The $M$-mode is preferred to the $R$-mode if and only if:

$$
V_{\delta} \geq V_{\gamma}+\frac{\left(m-V_{\gamma}\right)\left(f_{M}-f_{R}\right)+F_{M}-F_{R}}{v-f_{R}}
$$

If $f_{M}>f_{R}$ (respectively, $f_{M}<f_{R}$ ) then the $M$-mode is relatively more profitable when $m$ is low (respectively, when $m$ is high).

If both cost differences go in the same direction (i.e. $f_{M}-f_{R}$ and $F_{M}-F_{R}$ have the same sign), then the baseline tradeoff is unambiguously tilted in the direction of the lower-cost mode. On the other hand, if the fixed and variable cost differences go in opposite directions (i.e. $f_{M}-f_{R}$ and $F_{M}-F_{R}$ have opposite signs), then the effect of cost differences on the benchmark tradeoff is ambiguous. It depends on the magnitude of fixed cost savings relative to the magnitude of variable cost savings, and 
whether $m$ is high (i.e. "short-tail" or popular products) or if $m$ is low (i.e. "long-tail" or unpopular products). We explore the implications of this result for explaining why some products are offered in $M$-mode and some in $R$-mode in Section 4.3.

\subsection{Network effects with unfavorable expectations}

Previously, we have assumed that the number of buyers for each supplier does not depend on how many suppliers the buyer can purchase from. If buyers are more likely to come to an intermediary with more suppliers present (or offering more products), then suppliers' expectations can matter. To capture a possible cross-group network effect between suppliers and buyers, suppose $m$ increases in $n$. This could arise because the more products are made available, the more buyers will become aware of the intermediary (e.g. through word of mouth, reputation effects or other sources of information and review) or the more likely a given buyer that is informed about a particular product available through the intermediary will be to find other products of interest through the intermediary. In other words, we allow for positive agglomeration effects, contained in $m(n)$. We normalize $m \equiv m(N)$. To ensure $M$ is always profitable we add to (1) the new assumption that

$$
(v-f)\left(m(1)-V_{\gamma}\right)>F .
$$

The previous analysis remains valid in the presence of this network effect, provided $M$ benefits from favorable expectations - i.e. suppliers always coordinate on joining if they make non-negative profits in the resulting equilibrium. Since $m$ is increasing in $n$, the marketplace wants to sign up all $N$ suppliers. It charges them a participation fee equal to their expected profit (8), which assumes each expects all other suppliers to join when facing this fee. $R$ 's problem is also unaffected. Suppliers do not need to form expectations of how many other suppliers join when deciding whether or not to sell to $R$, since whether it is profitable to do so is independent of how many buyers show up.

Let us now examine the case in which suppliers hold unfavorable expectations, i.e. they coordinate on not joining the marketplace whenever this is an equilibrium. This scenario is particularly relevant for marketplaces that are part of early-stage ventures. Our treatment of unfavorable expectations follows Caillaud and Jullien (2003), Hagiu and Spulber (2013), and Halaburda and Yehezkel (2013).

The optimal choices of marketing by suppliers are unchanged compared to Section 3 because individual suppliers do not take into account the number of other suppliers that join when choosing their marketing activities. Thus, each individual supplier's expected net profit from joining $M$ when it expects $n^{e} \geq 0$ other suppliers to join is $(v-f)\left(m\left(n^{e}+1\right)-V_{\gamma}\right)-F-P$, where $P$ is the participation fee charged by $M$. We denote this profit $\pi\left(n^{e}+1\right)-P$. Note that $n^{e}$ depends on $P$ : we have chosen 
not to write $n^{e}(P)$ in order to avoid clutter. When suppliers hold unfavorable expectations, for any given $P$, each supplier expects no other supplier to join whenever this is an equilibrium, i.e. whenever $\pi(1)-P \leq 0$. In this case, if $M$ charges $P>\pi(1)$ then there is an equilibrium in which no suppliers join: each supplier expects no other suppliers to join, which implies she would make negative profits if she were to join on her own. Since this equilibrium prevails under unfavorable expectations, $M$ does not wish to set $P>\pi(1)$. Thus, the maximum price that $M$ can charge so that suppliers join is $P=\pi(1)$. At this price, the only equilibrium is that all $N$ suppliers offered the contract join, because they are willing to join irrespective of what they expect other suppliers to do. Given this, they must rationally expect all other suppliers to join when this participation fee is charged. The profit extracted by $M$ is therefore $N \pi(1)$, which is equal to

$$
\Pi_{M}=N\left((v-f)\left(m(1)-V_{\gamma}\right)-F\right) .
$$

Note that (15) is less than (9) given $m$ is increasing in $n$, so that unfavorable expectations lower $M$ 's profit. Assumption (14) ensures that $M$ still prefers to attract all $N$ suppliers. Comparing (15) with (5), we have:

Proposition 4 When $m$ is increasing in $n$ and the intermediary faces unfavorable expectations, the $M$-mode is preferred to the $R$-mode if and only if

$$
V_{\delta} \geq V_{\gamma}+m(N)-m(1)
$$

Unfavorable expectations shift the tradeoff unambiguously in favor of the $R$-mode, which may now be preferred even when the local information of individual suppliers is more important. The additional term on the right hand side of the inequality captures the size of the network effect. The $R$-mode allows the intermediary to sidestep the unfavorable expectations problem that the $M$-mode can run into. $^{7}$

There are two ways for $M$ to mitigate the problem arising from network effects and unfavorable expectations. One is to offer some products under the $R$-mode, an option we analyze in Section 4 . The other option is to charge a variable fee per unit of sales (if it can observe supplier sales). This can eliminate the need to set a fixed participation fee, and so reduces the role of network effects. In fact, if $M$ can pay suppliers to join, then it can completely overcome unfavorable expectations by subsidizing

\footnotetext{
${ }^{7}$ Using the same approach, we can derive the equilibrium under unfavorable expectations for the setting in Section 3.1, in which $m$ is constant and $x>0$. If suppliers hold unfavorable expectations, the marketplace can charge at most $P=\pi(1)=(v-f)\left(m-V_{\gamma}\right)-F$. Comparing this to the profits of a reseller, which are unchanged, the $M$-mode is preferred if and only if $V_{\delta} \geq V_{\gamma}+x \theta(N-1)+\frac{x^{2}(N-1)^{2}}{4}$. Since $x>0$, unfavorable expectations once again tilt the decision in favor of the $R$-mode, but the tradeoff remains otherwise the same.
} 
the suppliers' fixed participation costs and extracting all of their rents through variable fees. This leads to (almost) the same profits as under favorable expectations. Such subsidies may, however, not be feasible, for instance because they could lead to an adverse selection problem in which firms that are not genuine suppliers join simply to collect the subsidy. In the Appendix we prove:

Proposition 5 When $m$ is increasing in $n$, the intermediary faces unfavorable expectations, the marketplace can observe and condition on suppliers' sales but cannot subsidize suppliers to join the marketplace, the $M$-mode is preferred to the $R$-mode if and only if

$$
V_{\delta} \geq V_{\gamma}+\rho(m(N)-m(1))
$$

where

$$
\rho=\frac{F}{(v-f)\left(m(1)-V_{\gamma}\right)} \in(0,1) .
$$

Comparing (17) with (16), the effect of network effects is dampened by the multiplying factor $\rho$ which lies strictly between 0 and 1 . Thus, while the intermediary's choice is still unambiguously tilted towards the $R$-mode in the face of network effects and unfavorable expectations, variable fees do help to mitigate the effect.

\section{Hybrid modes}

So far we have focused on an intermediary that has to choose between the $M$-mode and the $R$-mode. In Section 3 we noted that an intermediary that could offer some products under each mode would not want to do so. In reality, intermediaries that sell products using both modes are quite prevalent. Amazon is a prominent example. As discussed in the introduction, Best Buy and department stores are other examples. In the sections that follow, we highlight several key factors which can make a hybrid mode optimal.

\subsection{Heterogenous information}

In our benchmark model, we have assumed the variances of supplier and intermediary information, respectively, are the same for all products. Suppose instead they are different, such that for all $i \in S_{R} \subset[N] \equiv\{1, . ., N\}$ we have $\operatorname{Var}\left(\gamma_{i}\right)>\operatorname{Var}\left(\delta_{i}\right)$, and for all $i \in S_{M}=[N] \backslash S_{R}$ we have $\operatorname{Var}\left(\gamma_{i}\right)<\operatorname{Var}\left(\delta_{i}\right)$. It is then straightforward to see:

Proposition 6 The intermediary's optimal strategy is to offer all products $i \in S_{R}$ in the $R$-mode and all products $i \in S_{M}$ in the $M$-mode. 
In other words, the intermediary should use the $R$-mode for all products where it has an information advantage over suppliers and the $M$-mode for all products where the advantage lies with suppliers.

\subsection{Heterogenous spillovers}

As we have seen, spillovers across products unambiguously shift the basic tradeoff in favor of the $R$ mode. If all spillovers are the same as we assumed in Section 3.1, then the optimal model is still either a pure reseller or a pure marketplace. In reality, spillovers may be asymmetric, i.e. some products generate larger spillovers than others. In such scenarios, if suppliers' information is more important than reseller information, it may be optimal to have some products offered in the $M$-mode (those products for which marketing does not generate any systematic and significant spillovers) and others offered in the $R$-mode (those products for which marketing generates a consistent and important spillover in one direction).

To illustrate, suppose there exists a partition of $[N]$ into two sets $S_{R}$ and $S_{M}=[N] \backslash S_{R}$, such that all products $i \in S_{R}$ generate spillovers equal to $x$ among each other but no spillovers on products $i \in S_{M}$, and products $i \in S_{M}$ generate no spillovers whatsoever. Then the profits of the intermediary can be decomposed into the two sets of products, with the profits being separable across the two groups. Thus, Proposition 2 applies to the group of products in $S_{R}$ and Proposition 1 applies to the group of products in $S_{M}$. We obtain:

Proposition 7 Suppose all products $i \in S_{R}$ generate spillovers equal to $x$ on each other, while products $i \in S_{M}$ do not generate nor receive any spillovers. The intermediary chooses the interior hybrid mode in which it offers products $i \in S_{R}$ under the $R$-mode and products $i \in S_{M}$ under the $M$-mode if and only if

$$
V_{\gamma}<V_{\delta} \leq V_{\gamma}+\frac{\left(N_{R}-1\right)^{2} x^{2}}{4}
$$

Otherwise, if $V_{\delta} \leq V_{\gamma}$ then the intermediary chooses the pure $R$-mode; if $V_{\delta}>V_{\gamma}+\frac{\left(N_{R}-1\right)^{2} x^{2}}{4}$ then the intermediary chooses the pure $M$-mode.

Clearly the pure $R$-mode dominates if $V_{\delta} \leq V_{\gamma}$. Not only does $R$ have an information advantage for all products, but it can fully internalize the effect of the spillovers between products in $S_{R}$. If $V_{\delta}>V_{\gamma}$, then the information advantage rests with the suppliers, so the $M$-mode is preferred for those products in $S_{M}$ for which there are no spillovers. If $V_{\delta}$ is sufficiently high, this information advantage will more than offset the benefit of coordinating marketing activities, and the intermediary will prefer the $M$-mode even for the products in $S_{R}$. 
A more interesting case arises if the spillovers generated from products in $S_{R}$ extend to all products. In this case, even if the intermediary controls all products in $S_{R}$ under the $R$-mode it will still not internalize all the spillovers they create. There can then be a role for offering some additional products (i.e. some from $S_{M}$ ) in the $R$-mode. In the appendix, we prove:

Proposition 8 Suppose all products $i \in S_{R}$ generate spillovers equal to $x$ on all other products, while products $i \in S_{M}$ do not generate any spillovers. Assume $N_{R}^{2}+N_{R}>2 N-1$. Then the optimal mode is:

- pure $R$-mode if $V_{\delta}-V_{\gamma} \leq \frac{x^{2}}{4} N_{R}$

- sell $N_{R}$ products in $S_{R}$ and $k^{*}$ products from $S_{M}$ under the $R$-mode and all other products under the $M$-mode if $\frac{x^{2}}{4} N_{R} \leq V_{\delta}-V_{\gamma} \leq \frac{x^{2}}{4}\left(1-N_{R}^{2}+2 N\left(N_{R}-1\right)\right)$, where $k^{*} \in\left[1, N-N_{R}-1\right]$ satisfies the following bounds

$$
\left(N-N_{R}\right)-\frac{2\left(V_{\delta}-V_{\gamma}\right)}{N_{R} x^{2}}-\frac{1}{2}<k^{*}<\left(N-N_{R}\right)-\frac{2\left(V_{\delta}-V_{\gamma}\right)}{N_{R} x^{2}}+\frac{1}{2}
$$

- pure $M$-mode if $V_{\delta}-V_{\gamma} \geq \frac{x^{2}}{4}\left(1-N_{R}^{2}+2 N\left(N_{R}-1\right)\right)$.

Once again, the pure $R$-mode dominates if $V_{\delta} \leq V_{\gamma}$. In case $V_{\delta}>V_{\gamma}$, the intermediary now faces a tradeoff. Suppliers within $S_{M}$ enjoy an information advantage, but, by taking control of some products from $S_{M}$, the intermediary can better internalize the spillovers generated by the marketing choices of products in $S_{R}$. This also raises the amount that independent suppliers are willing to pay to join, given that the marketing activities of products in $S_{R}$ are better optimized in terms of the spillovers they create.

\subsection{Heterogeneous products and cost differences}

Suppose the value of $m$ differs across products so that $m_{1} \leq m_{2} \leq \ldots \leq m_{N}$ with at least one inequality strict. Some products are long-tail products (have low $m_{i}$ ) and some products are short-tail products (have high $m_{i}$ ). Furthermore, assume there are cost differences as in Section 3.2. Then the profit the intermediary obtains from product $i$ if it operates in the $R$-mode is $\left(v-f_{R}\right)\left(m_{i}-V_{\delta}\right)-F_{R}$. Allowing $M$ to set different participation fees for the different products to reflect the different values of $m$, the profit the intermediary obtains from product $i$ if it operates in the $M$-mode is $\left(v-f_{M}\right)\left(m_{i}-V_{\gamma}\right)-F_{M}$. Then it follows: 
Proposition 9 If $f_{M}>f_{R}$ (respectively, $f_{M}<f_{R}$ ) then the intermediary's optimal strategy is to offer products $i$ such that $m_{i} \leq m^{*}$ in the $M$-mode (respectively, $R$-mode) and products $i$ such that $m_{i}>m^{*}$ in the $R$-mode (respectively, $M$-mode), where the cutoff $m^{*}$ is given by

$$
m^{*}=\frac{V_{\delta}\left(v-f_{R}\right)-V_{\gamma}\left(v-f_{M}\right)+F_{R}-F_{M}}{f_{M}-f_{R}} .
$$

In other words, when the marketplace has a variable cost disadvantage (i.e. when $f_{M}>f_{R}$ ), an intermediary facing heterogeneous product demands should sell long-tail products in the $M$-mode and short-tail products in the $R$-mode. And vice versa when the marketplace has a variable cost advantage. We discuss empirical implications of and evidence for this result in Section 6.

\subsection{Unfavorable expectations}

Suppose, as in Section 3.3, that $m$ is increasing in $n$, i.e. there are network effects. In this case, the presence of unfavorable expectations creates a natural reason for the intermediary to choose a hybrid strategy: offer a sufficient number of products under the $R$-mode in order to overcome unfavorable expectations, but not too many if suppliers' local information is more important than the intermediary's.

Suppose the intermediary offers $0 \leq n_{R} \leq N$ products under the $R$-mode and $\left(N-n_{R}\right)$ products under the $M$-mode. Unfavorable expectations means that independent suppliers expect the intermediary will only be able to offer the $n_{R}$ products it has bought as a reseller whenever it is an equilibrium for the independent suppliers not to affiliate (i.e. when their surplus is negative if they each assume all the other independent suppliers do not affiliate). Thus, the amount the intermediary can extract from independent suppliers (if $\left.n_{R}<N\right)$ is

$$
\left(N-n_{R}\right)\left((v-f)\left(m\left(n_{R}+1\right)-V_{\gamma}\right)-F\right) .
$$

Its profit from selling the remaining $n_{R}$ products itself is

$$
n_{R}\left((v-f)\left(m(N)-V_{\delta}\right)-F\right) .
$$

Adding the two components of profit, the intermediary's expected profit is

$$
\Pi\left(n_{R}\right)=(v-f)\left(\begin{array}{c}
\left(N-n_{R}\right) m\left(n_{R}+1\right)+n_{R} m(N) \\
-\left(N-n_{R}\right) V_{\gamma}-n_{R} V_{\delta}
\end{array}\right)-n F .
$$


Since $m(N)>m\left(n_{R}+1\right)$ and since $m\left(n_{R}+1\right)$ is increasing in $n_{R}$ for $n_{R}<N-1$, the first term in square brackets is unambiguously increasing in $n_{R}$ up to $n_{R}=N-1$. This represents the fact that the $R$-mode allows the intermediary to avoid unfavorable expectations, so shifting more products to this mode increases profit. By itself, this term would push the intermediary to offer all products in the $R$-mode. ${ }^{8}$ However, if $V_{\delta}>V_{\gamma}$, then the second term in square brackets is decreasing in $n_{R}$. This is due to the informational advantage of suppliers in the $M$-mode. Thus, there can be a tradeoff. Offering more products in the $R$-mode helps overcome unfavorable expectations but it loses valuable supplier information. The following proposition is proven in the appendix.

Proposition 10 Suppose $m\left(n_{K}\right)=m-\alpha\left(N-n_{K}\right)$ for $1 \leq n_{K} \leq N$, with $\alpha>0$. If $V_{\delta} \leq V_{\gamma}$, then the intermediary will choose to offer all products in the $R$-mode. If $V_{\gamma}<V_{\delta}<V_{\gamma}+2 \alpha(N-1)$, the intermediary will adopt a hybrid mode. If $V_{\delta} \geq V_{\gamma}+2 \alpha(N-1)$, the intermediary will offer all products in the $M$-mode. In the case that the intermediary adopts the hybrid solution, the optimal number of products $n_{R}^{*}$ offered in the $R$-mode is bounded by the inequalities

$$
N-1-\frac{V_{\delta}-V_{\gamma}}{2 \alpha}<n_{R}^{*}<N-\frac{V_{\delta}-V_{\gamma}}{2 \alpha}
$$

If $V_{\delta} \leq V_{\gamma}$, then the $R$-mode dominates both on informational grounds and as a way to overcome unfavorable expectations. When $V_{\delta}>V_{\gamma}$, offering $N-1$ products in the $R$-mode fully overcomes pessimistic expectations, leaving one product to be offered in the $M$-mode to exploit the information advantage suppliers have in this case. Of course, once $V_{\delta}$ is sufficiently large relative to $V_{\gamma}$, it is optimal to offer all products in the $M$-mode. Note the bounds in (20) for the optimum number of products sold in the $R$-mode are decreasing in $V_{\delta}-V_{\gamma}$ (consistent with an informational advantage driving the choice between the two modes) and increasing in the magnitude of network effects $\alpha$ (consistent with the finding of 3.3 that network effects are detrimental to the $M$-mode under unfavorable expectations).

\section{Robustness}

In this section we discuss the implications of some modifications to our setup, which are meant to highlight the robustness and general nature of the insights we have drawn.

\footnotetext{
${ }^{8}$ Note selling $N-1$ products in the $R$-mode and one in the $M$-mode would be equivalent to selling all $N$ in the $R$-mode from the perspective of overcoming unfavorable expectations.
} 


\subsection{Costly marketing activities}

Consider an alternative formulation of marketing activities. Rather than representing them as horizontal choices, we now assume marketing activities $a_{i}$ represent the actual levels of investment in marketing through or on the intermediary, and that the marginal effectiveness of marketing activities is proportional to $a_{i}^{*}$. Specifically, demand for product $i$ is

$$
m+2\left(\theta+\gamma_{i}+\delta_{i}\right) a_{i}
$$

where $\theta, \gamma_{i}$ and $\delta_{i}$ satisfy the same assumptions as before. ${ }^{9}$ Investing $a_{i}$ in marketing activities implies a cost $\kappa a_{i}^{2}$, which is incurred by the supplier ( $M$-mode) or by the intermediary ( $R$-mode). Thus, additional spending on marketing activities increases demand, although with diminishing returns. We have in mind costly activities that bring in additional buyers by making them more aware of the product being marketed. The assumption of private information captures that suppliers and intermediaries may each have some information about how effective spending on marketing activities will be for a given product.

In the Supplementary Appendix we show that our main results from Section 3 carry through. In particular, Propositions 1 and 2 are unchanged. The formulas in Propositions 3, 4 and 5 are somewhat modified but the key tradeoffs remain the same.

\subsection{Supplier bargaining power}

Up to now we have assumed the intermediary held all the bargaining power: it made take-it-or-leaveit offers to suppliers in stage 1 and extracted their entire expected surplus under both modes. It is straightforward to extend our model to scenarios in which suppliers have positive bargaining power. Suppose, consistent with our timing of offers, bargaining occurs in stage 1. To do so, suppose suppliers have bargaining power $\beta \in[0,1]$, meaning that each supplier will only be agreeable to deal with the intermediary if the supplier retains a fraction $\beta$ of the expected joint profit she generates, with the remaining fraction $(1-\beta)$ retained by the intermediary. This could either be done by reducing the participation fee charged by the marketplace or by making a fixed payment to the supplier in the case of a reseller (or equivalently, by increasing the wholesale price paid to the supplier).

In the Supplementary Appendix we show that, once again, our main results from Section 3 carry through. In particular, Propositions 1, 2 and 3 are unchanged. The analysis corresponding to Propositions 4 and 5 is somewhat modified but the key results remain the same. The only difference is that when supplier bargaining power is above a certain threshold, the effect of unfavorable expectations

\footnotetext{
${ }^{9}$ The constant 2 normalizes the marginal effectiveness of $a_{i}$ to be the same as in our benchmark specification.
} 
disappears completely and the benchmark tradeoff from Proposition 1 is restored. The explanation is as follows: if supplier bargaining power is sufficiently strong then the participation fees charged to suppliers are low anyway, so that all suppliers want to participate regardless of their expectations about what other suppliers will do. In this case, the nature of expectations is no longer relevant to the tradeoff between the two modes.

\subsection{Downward-sloping demand from suppliers}

We have assumed that in the absence of network effects, both $M$ and $R$ can extract the entire expected surplus from suppliers. This was either because suppliers (and their products) were completely symmetric or, where they were not, because we implicitly assumed that intermediaries ( $M$ in particular) could price discriminate, i.e. $M$ could observe any heterogeneity across suppliers and set different participation fees accordingly.

It is straightforward to extend our model to accommodate heterogeneity across products, such that the heterogeneous parameter (e.g. different $m_{i}$ 's across products) is unobservable to the intermediary. In this case, the intermediary would be unable to extract the full supplier surplus and would therefore face a supplier demand for participation that is downward-sloping in the price(s) charged (under both modes). As long as the heterogeneous parameter does not affect marketing activities (for instance, heterogeneity in $m$ has no bearing on the choices of marketing activities), our main results and conclusions go through unchanged. In the Supplementary Appendix we provide a brief illustration of this point with heterogeneous $m$.

\subsection{Buyer surplus and affiliation}

We have assumed that buyer affiliation with the intermediary was costless and that the intermediary and/or the suppliers were able to extract the entire buyer surplus in all scenarios. These features of our model allowed us to avoid introducing any pricing distortions in the analysis. Our model can, however, be extended such that: (i) buyers incur heterogeneous opportunity costs when joining the intermediary (either $M$ or $R$ ); and (ii) buyers have positive bargaining power, which allows them to retain some surplus from their transactions with $R$ or the individual suppliers. In particular, we can allow $R$ to have greater (or equal) bargaining power over buyers relative to individual suppliers. This fits real-world scenarios in which $R$ aggregates the bargaining powers of many individual suppliers, such as for example Intellectual Ventures in the market for patents (see Hagiu and Wright 2013 and Hagiu and Yoffie 2013).

It is straightforward to show that in this context our main tradeoffs remain unchanged. The 
benchmark tradeoff is simply augmented by terms which reflect the new differences between $M$ and $R$, namely that the $R$-mode allows the intermediary to extract more rents from buyers, but, for this exact reason, the $M$-mode attracts a larger number of buyers, as they expect to obtain a larger net surplus. The formalization of these results is contained in the Supplementary Appendix.

\subsection{Other non-contractible decision variables}

Throughout the paper, we have chosen to focus on marketing activities as the key non-contractible decision driving the difference between the two modes. As discussed in the introduction, however, there are other potentially non-contractible decisions that one could focus on. For example, if there are privately observed demand shocks, similar tradeoffs to those we have derived will arise when the non-contractible decisions are product prices rather than marketing activities. Consider the simplest possible setting. Suppose each supplier offers a single product, is subject to linear demand, and all variable costs are set to zero. The level of demand for each product is subject to two demand shocks, one which is only observed by the corresponding supplier and one which is only observed by $R$. For this case, one can show that essentially the same tradeoffs arise as in our benchmark model. The extent to which the $M$-mode is preferred over the $R$-mode boils down to whether the local information on demand by suppliers is more important (has higher variance) than the local information of the intermediary. In the case that products are independent, the tradeoff is in fact identical to our benchmark result in Proposition 1. Relative to this, the choice is shifted towards the $R$-mode to the extent there is a spillover in demand, which will be the case if products are substitutes or complements. This shows the result of Proposition 2 continues to apply.

\section{Empirical implications}

In this section we discuss some empirical illustrations of and evidence for our main results.

Consider our baseline result from Proposition 1 and its extension to the case with heterogenous information in Proposition 6: the marketplace-mode is preferred to the reseller-mode whenever the local information held by suppliers is more important than the local information held by the reseller. Three real-world examples illustrate this result: Amazon with respect to books and electronics, department stores and BestBuy.

Amazon started off in 1994 as a reseller of books; it added the electronics category in 1999. Furthermore, the products under the electronics category change notoriously fast. As a result, Amazon likely has more of an information disadvantage relative to its suppliers with respect to electronics than with respect to books. We therefore expect that Amazon should sell a lower proportion of 
the electronics category as a reseller, relative to the books category. High-level data gleaned from Amazon's website confirms this prediction. In January 2014, under the category "Books", Amazon listed 20,468,847 new books in stock. Amazon is listed as a seller for 11,007,702 of these, so over 50\%. Under the category "Electronics", Amazon listed 25,851,049 new items in stock. Amazon is listed as a seller for only 357,283 of these, i.e. just over $1 \%$.

Department stores have traditionally offered cosmetics products through dedicated "counters" where displays are designed and controlled by individual brands (and sales staff are assigned exclusively to and trained by specific brands) as in the $M$-mode, whereas other products (e.g. mass-market accessories such as watches, scarves, jewelry) are offered on displays controlled by the store and serviced by generalist sales personnel as in the $R$-mode. Indeed, cosmetics brands have highly specialized knowledge about how best to market specific products to consumers, which is hard for stores and their sales staff to accumulate (Koehn 2002). Such specialized knowledge is less important for mass-market accessories. Similarly, whereas many electronics manufacturers are content to let Best Buy control the sale of their products to consumers, Apple, Microsoft and Samsung have recently decided to run their own mini-stores within Best Buy based on the premise that they have superior information on how best to pitch their products to consumers. Finally, this tradeoff is also relevant in explaining why some digital content intermediaries such as Amazon's Kindle Store, Apple's iBooks Store, Apple's App Store and Google Play have adopted the marketplace mode, in which content or application suppliers control pricing, end-user licensing and customer support.

Let us now turn to the three other key factors that affect the baseline tradeoff. First, if marketing activities (or other non-contractible decisions) generate spillovers across products, the reseller-mode becomes more attractive (see Propositions 2 and 7). This is because a reseller can internalize these externalities when it exerts its control rights, something that independent suppliers acting in an uncoordinated fashion cannot do. Thus, it would probably not make sense for BestBuy to allow all of its suppliers to operate independent mini-stores. Indeed, given the inherent competition between brands for consumer attention, the result would likely be an over-investment in brand-specific promotional activities (signage, sales staff, etc.). Spillovers are also an important factor in explaining why cable TV operators predominately choose to operate in the reseller-mode, extracting more value by coordinating their pricing and marketing decisions across different channels (e.g. through bundling, and the cross marketing of different channels).

Second, Propositions 3 and 9 imply that when the reseller has lower marginal costs of handling additional sales of the same product than the marketplace, the tradeoff between the two modes depends on the level of demand for each product. The baseline tradeoff is shifted in favor of the marketplace when the intermediary handles a broad range of long-tail products (e.g. e-Bay, Etsy.com, the Flea 
Market of Saint-Ouen in Paris) and in favor of the reseller when the intermediary is considering a more focused range of short-tail products (e.g. Eastbay, an online retailer focused mainly on athletic shoes; Gazelle, an online service that buys and resells used smartphones and tablets, focusing only on the most popular models).

To specifically illustrate the result in Proposition 9, consider the example of Amazon. Thanks to its massive infrastructure investments, Amazon has lower variable costs of handling and marketing any given product on its site than third-party merchants. Therefore, our model predicts Amazon should sell short-tail products under the $R$-mode and long-tail products under the $M$-mode. This prediction is consistent with descriptions of Amazon's strategy with respect to third-party sellers. Amazon oftentimes enters new product categories by allowing third-party merchants to sell the products in question (marketplace mode). If a product category becomes successful (i.e. if sales exceed a certain threshold), then Amazon starts selling the relevant products in the reseller mode (see Stone 2013, pp. 303-304). In other words, once Amazon reaches information parity with its sellers, it switches to the reseller mode in order to exploit its scale advantage.

We have tested this prediction more rigorously using data from Amazon. We extracted the unique product identifiers and Amazon's sales ranks in the category "Movies \& TV" for all 583,779 DVDs listed by Amazon under "Movies \& TV" which were in stock in early January 2014. ${ }^{10}$ Amazon does not disclose exactly how it measures sales rank but it is widely understood that it is a relative measure of the popularity of items within a given product category (in this case "Movies \& TV") based on their recent and past sales history. High-selling items have low rankings (i.e. closer to \#1) while items that seldom sell having rankings which can be in the millions. We randomly drew 10,000 product identifiers and for each of them we recorded whether or not Amazon sold that DVD. Amazon was listed as a seller for $35.74 \%$ of these DVDs. Of the 10,000 sampled DVDs, 2,759 did not have a sales rank, reflecting they had not had any recent sales on Amazon. Amazon was listed as a seller on only $12.11 \%$ of these 2,759 DVDs, a strong indication that it avoids trying to sell "long-tail" (unpopular) items.

When we included data on items with no sales rank, we set their sales rank equal to one plus the maximum of the reported sales ranks over the 583,779 DVDs, in order to capture that they are less popular than the least popular item with recent sales. Measured in this way, the median sales rank for those DVDs where Amazon is listed as a seller is 355,793 . This compares to a median sales rank of 812,332 for DVDs where Amazon is not listed. Even if we drop items with no sales rank, the median sales rank for those DVDs where Amazon is listed as a seller is 304,499, compared to a

\footnotetext{
${ }^{10}$ Since Amazon only listed the top 9600 items on any search, this required collecting the information by conducting searches in narrow price ranges. All items can be obtained by combining the results of these different searches.
} 


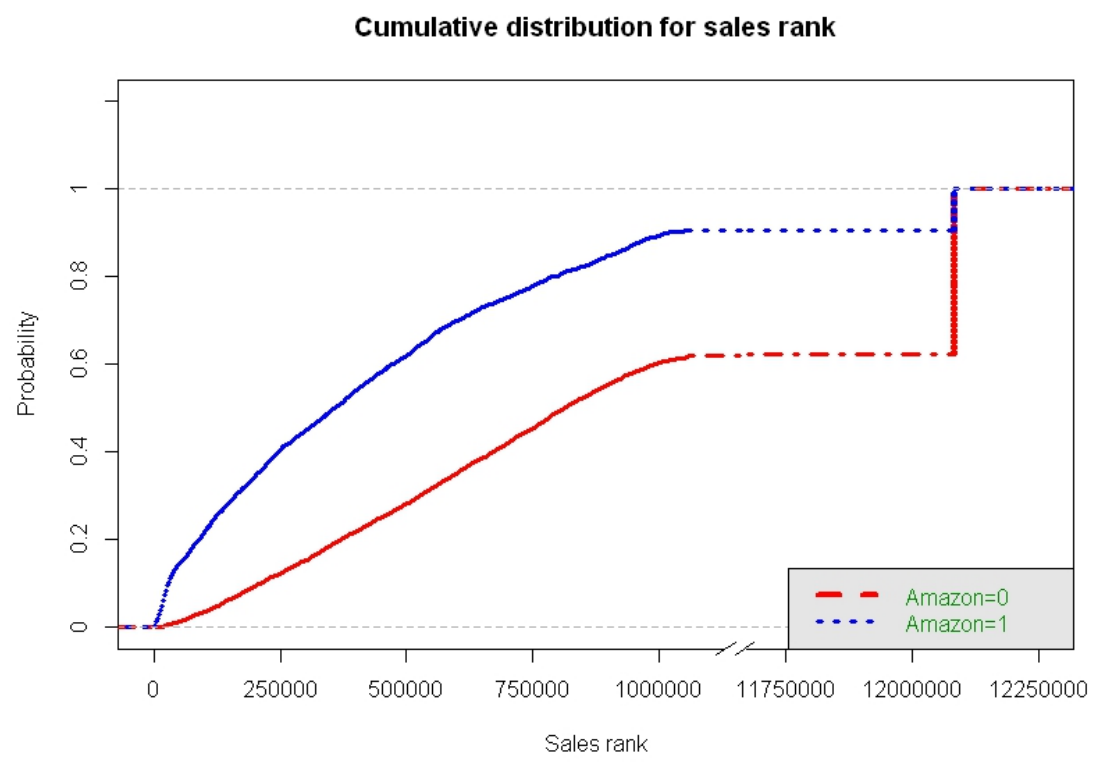

Figure 1: CDFs of sales rank for DVDs sold by Amazon and those not sold by Amazon

median sales rank of 540,572 for DVDs where Amazon is not listed. Regardless of how sales ranks are treated, a two-sided Wilcoxon test of the null hypothesis that two groups (sold by Amazon and not sold by Amazon) have identical distribution functions against the alternative hypothesis that the two distribution functions differ in their median easily rejects the null hypothesis in favor of the alternative that the group in which Amazon sells has lower sales ranks (i.e. more popular products). ${ }^{11}$

Figure 1 plots the cumulative distribution function $(\mathrm{CDF})$ of sales ranks (i.e. the probability that sales rank is less than any given number) for each of the two groups. It shows clearly that the DVDs sold by Amazon (Amazon =1) take up a much higher proportion of the very popular DVDs and a much lower proportion of the DVDs with no sales or those that are very unpopular (as indicated by their sales ranks).

The third key factor we explored was network effects. Specifically, if more suppliers attract more buyers per supplier, and the marketplace faces unfavorable expectations (a common occurrence for early-stage marketplace ventures) then the baseline tradeoff is shifted in favor of the reseller. Indeed, operating as a reseller allows the intermediary to side-step the chicken-and-egg problem which plagues early-stage marketplaces. Thus, when starting up, intermediaries should consider adopting the reseller mode, given they are more likely to face a problem of unfavorable expectations initially. Once they overcome such unfavorable expectations, they can switch to the marketplace-mode. Thus, our analysis formalizes the discussion of two-sided platforms' start-up strategies in Hagiu and Eisenmann (2007).

\footnotetext{
${ }^{11}$ The p-values are less than $2.2 \mathrm{E}-16$ in both cases, so essentially zero. Note the Wilcoxon rank-sum test is particularly suitable for this exercise since it is robust to rank data of the type we use here.
} 
This approach was adopted by Amazon, who initially bought and resold books and other products. After it established a substantial base of buyers, the company first moved to open up a marketplace for attracting independent suppliers in 1999, four years after its initial launch (Casadesus-Masanell and Thaker 2012). By 2011, the marketplace accounted for 30\% of unit sales on Amazon.com (Hagiu and Wright 2013).

\section{Conclusions and managerial implications}

We have established several fundamental tradeoffs faced by an intermediary when choosing whether to function more as a marketplace or more as a reseller. We have also discussed some empirical implications of these tradeoffs. Our model's predictions have clear managerial implications. To summarize, intermediaries should choose the marketplace (respectively, reseller) mode for the following types of products: (1) products for which suppliers have a significant (respectively, a small) information advantage about the best way to market products relative to the intermediary; (2) products whose prices and marketing activities have limited (respectively, large) spillovers on other products; (3) long-tail (respectively, short-tail) products when the marketplace mode has a marginal cost disadvantage (respectively, advantage); and (4) products provided by late stage (respectively, early stage) ventures. These implications not only apply to an intermediary choosing between positioning itself as a pure reseller or a pure marketplace, but also to hybrid modes in which the intermediary needs to determine how many products (and, in the case of heterogenous products, which products) to offer in each mode.

Our analysis has provided a new style of modeling intermediaries' strategic positioning decisions. There are many promising directions in which this analysis can be extended. One could generalize our analysis to allow for multiple non-contractible decisions, such as different types of marketing activities, store design, customer service, inventory management, returns management, after-sale service, delivery options, pricing, payment, etc. We could allow the intermediary to take control of some of these decisions and not others. If different decision variables have different distributions of supplier and intermediary information, and different degrees of spillovers associated with them, then it is quite possible that a different type of hybrid mode would arise, with the intermediary controlling some decisions and leaving others for suppliers to control. Considering all possible combinations of the allocation of control rights over these different decisions would map out a fine-grained spectrum of models, from a pure marketplace in which all decisions are controlled by suppliers to a pure reseller in which all are controlled by the intermediary.

Another important direction for future research is to relax the assumption that buyers must go through the intermediary in order to reach suppliers. This need not be the case. The possibility of 
disintermediation may be of particular concern under the marketplace mode given that suppliers and buyers get to interact directly, thereby constraining the level (and type) of fees that the marketplace can charge, and shifting an intermediary's choice towards the reseller mode. Related to this point, one could embed the choice of intermediation mode into a framework in which the intermediary arises endogenously, in response to some friction (e.g. search costs or transaction costs) from direct trading between suppliers and buyers. Finally, one could study competing intermediaries, and whether there is a tendency for different intermediation modes to emerge, possibly in a complementary relationship, or for one mode to drive out the other. Where different modes do emerge, they could appeal to different types of suppliers and buyers, and it would be interesting to study which types of suppliers and buyers are attracted to each mode.

\section{References}

[1] Alonso, R., W. Dessein and N. Matouschek (2008) "When Does Coordination Require Centralization?" American Economic Review, 98(1), 145-179.

[2] Alonso, R., W. Dessein and N. Matouschek (2013) "Organizing to Adapt and Compete," Working Paper.

[3] Armstrong, M. (2006) "Competition in Two-Sided Markets," Rand Journal of Economics, 37 (3), 669-691

[4] Bakos, J. Y. (1997) "Reducing Buyer Search Costs: Implications for Electronic Marketplaces," Management Science, 43(12), 1676-1692.

[5] Boudreau, K.J. (2010) "Open Platform Strategies and Innovation: Granting Access vs. Devolving Control," Management Science 56(10), 1849-1872.

[6] Caillaud, B. and B. Jullien (2003) "Chicken and Egg: Competition Among Intermediation Service Providers," Rand Journal of Economics, 34(2), 309-328

[7] Casadesus-Masanell and Thaker (2012) "eBay, Inc. and Amazon.com (A)," Harvard Business School case study $712-405$.

[8] Eisenmann, T., G. Parker and M. Van Alstyne (2011) "Platform Envelopment," Strategic Management Journal, 32 (12), 1270-1285.

[9] Foros, O., H-J. Kind and G. Shaffer (2013) "Turning the Page on Business Formats for Digital Platforms: Does Apple's Agency Model Soften Competition?" Working Paper. 
[10] Gans, J. (2012) "Mobile Application Pricing," Information Economics and Policy 24, 52-59.

[11] Gawer, A. and M. Cusumano (2008) "How Companies Become Platform Leaders," MIT Sloan Management Review, 49, 28-35.

[12] Gawer, A. and R. Henderson (2007) "Platform Owner Entry and Innovation in Complementary Markets: Evidence from Intel," Journal of Economics \& Management Strategy, 16(1), 1-34.

[13] Gawer, A. and N. Phillips (2013) "Institutional Work as Logics Shift: The case of Intel's Transformation to Platform Leader," Organization Studies, 1-37.

[14] Grossman, S. and O. Hart (1986) "The Costs and Benefits of Ownership: A Theory of Vertical and Lateral Ownership," Journal of Political Economy, 94, 691-719.

[15] Hagiu, A. (2007) "Merchant or Two-Sided Platform," Review of Network Economics 6 (2), 115133.

[16] Hagiu, A. and T. Eisenmann (2007) "A Staged Solution to the Catch-22," Harvard Business Review 85 (11).

[17] Hagiu, A. and B. Jullien (2011) "Why Do Intermediaries Divert Search?" Rand Journal of Economics, 42 (2), 337-362.

[18] Hagiu, A. and R. S. Lee (2011) "Exclusivity and Control," Journal of Economics \& Management Strategy, 20 (3), 679-708.

[19] Hagiu, A. and D. Spulber (2013) "First-Party Content and Coordination in Two-Sided Markets," Management Science 59(4), 933-949.

[20] Hagiu, A., and J. Wright (2011) "Multi-Sided Platforms," Harvard Business School Working Paper No. 12-024.

[21] Hagiu, A. and J. Wright (2013) "Do You Really Want to Be an eBay?" Harvard Business Review 91 (3), 102-108.

[22] Hagiu, A. and D. B. Yoffie (2013) "The New Patent Intermediaries: Platforms, Defensive Aggregators and Super-Aggregators." Journal of Economic Perspectives, 27(1), 45-66.

[23] Halaburda, H. and Y. Yehezkel (2013) "Platform Competition under Asymmetric Information," American Economic Journal: Microeconomics, 5(3), 22-68 
[24] Hart, O., and J. Moore (1990) "Property Rights and the Nature of the Firm," Journal of Political Economy, 98, 1119-1158.

[25] Johnson, J.P. (2013a) "The Agency Model and MFN Clauses," Available at SSRN: http://ssrn.com/abstract $=2126808$.

[26] Johnson, J.P. (2013b) "The Agency and Wholesale Models in Electronic Content Markets," Available at SSRN: http://ssrn.com/abstract $=2126808$.

[27] Koehn, N. F. (2002) "Estee Lauder and the Market for Prestige Cosmetics," Harvard Business School case study 801-362.

[28] Nocke, V., Peitz, M. and Stahl, K. (2007) "Platform Ownership," Journal of the European Economic Association, 5, 1130-1160.

[29] Parker, G. and M. W. Van Alstyne (2005) "Two-Sided Network Effects: A Theory of Information Product Design," Management Science, 51, 1494-1504

[30] Parker, G. and M. W. Van Alstyne (2012) "Innovation, Openness and Platform Control," Working Paper, Tulane University, Boston University and MIT.

[31] Rochet, J.-C., and J. Tirole (2003) "Platform Competition in Two-Sided Markets," Journal of the European Economic Association, 1, 990-1029.

[32] Rochet, J.-C. and J. Tirole (2006) "Two-Sided Markets: Where We Stand," Rand Journal of Economics, 37 (3), 645-66.

[33] Rysman, M. (2009) "The Economics of Two-Sided Markets," Journal of Economic Perspectives, $23,125-143$.

[34] Stone, B. (2013) The Everything Store - Jeff Bezos and the Age of Amazon, New York, NY: Little, Brown and Company.

[35] Williamson, O. (1975) Markets and Hierarchies: Analysis and Antitrust Implications, New York, NY: Free Press. 


\section{A Appendix - Proofs}

\section{Proof of Proposition 5}

If $M$ can monitor supplier sales and charge a variable fee $p$ in addition to a non-negative fixed fee $P$, each individual supplier's expected profit from joining $M$ is $(v-p-f)\left(m\left(n^{e}\right)-V_{\gamma}\right)-F-P$. Under unfavorable expectations $P(p)=(v-p-f)\left(m(1)-V_{\gamma}\right)-F$, implying $M$ 's expected profit is

$$
\begin{aligned}
\Pi_{M}^{U E}(p, n) & =n\left(P(p)+p\left(m(n)-V_{\gamma}\right)\right) \\
& =n\left((v-f)\left(m(1)-V_{\gamma}\right)+p(m(n)-m(1))-F\right)
\end{aligned}
$$

if $n$ suppliers participate. Given $m(n)>m(1), \Pi_{M}^{U E}(p, n)$ is strictly increasing in $p$ provided $v-p-f>0$ so that the supplier still wants to sell units and choose the optimal level of marketing activities. Then $M$ optimally sets the highest possible $p$ such that $P \geq 0$. This is

$$
p=v-f-\frac{F}{m(1)-V_{\gamma}} .
$$

Note $0<p<v-f$ given (14). At this price $p$, profits are clearly increasing in $n$ so $M$ optimally sets $n=N$. Its expected profit is

$$
N\left((v-f)\left(m(N)-V_{\gamma}\right)-\frac{m(N)-V_{\gamma}}{m(1)-V_{\gamma}} F\right)
$$

which can be compared to $R$ 's expected profit in (5). The comparison gives the expression in (17). The term $\rho$ in (17) satisfies $0<\rho<1$ given (14).

\section{Proof of Proposition 8}

First, note that it is never optimal to sell any product $i \in S_{M}$ in the $R$-mode if there is at least one product $j \in S_{R}$ sold in the $M$-mode. Indeed, one could then profitably switch product $i$ to the $M$-mode and product $j$ to the $R$-mode. The only impact on profit would arise from the fact that marketing for $j$ creates spillovers which the $R$-mode internalizes while the $M$-mode does not. This implies that the intermediary should consider selling some products from $S_{M}$ in the $R$-mode only if all products in $S_{R}$ are sold in the $R$-mode.

Second, we show it is never optimal to sell some but not all products from $S_{R}$ in the $M$-mode. Let $S_{0}$ denote the set of $k \leq N_{R}$ products within $S_{R}$ that are sold under the $M$-mode. Then, for all $i \in S_{0}$, the optimal choice of marketing is $a_{i}=\theta+\gamma_{i}+x\left(N_{R}-k-1\right) / 2$. For all other $j$, the choice of marketing is $a_{j}=\theta+\delta_{j}$. Resulting intermediary profits are

$$
\begin{aligned}
\Pi(k)= & (v-f) \sum_{i \in S_{R} \backslash S_{0}} E\left[m-\left(\frac{x\left(N_{R}-k-1\right)}{2}-\delta_{i}\right)^{2}+x\left(\begin{array}{c}
\sum_{j \neq i, j \in S_{R} \backslash S_{0}}\left(\theta+\gamma_{j}+\frac{x\left(N_{R}-k-1\right)}{2}\right) \\
+\sum_{j \in S_{0}}\left(\theta+\delta_{j}\right)
\end{array}\right)\right] \\
& +(v-f) \sum_{i \in S_{0}} E\left[m-\gamma_{i}^{2}+x\left(\sum_{j \in S_{R} \backslash S_{0}}\left(\theta+\gamma_{j}+\frac{x\left(N_{R}-k-1\right)}{2}\right)+\sum_{j \neq i, j \in S_{0}}\left(\theta+\delta_{j}\right)\right)\right] \\
& (v-f) \sum_{i \in S_{M}} E\left[m-\gamma_{i}^{2}+x\left(\sum_{j \in S_{R} \backslash S_{0}}\left(\theta+\gamma_{j}+\frac{x\left(N_{R}-k-1\right)}{2}\right)+\sum_{j \in S_{0}}\left(\theta+\delta_{j}\right)\right)\right]-N F \\
= & (v-f)\left(\begin{array}{c}
\left(N_{R}-k\right)\left(V_{\gamma}-V_{\delta}-\frac{x^{2}\left(\left(N_{R}-k\right)^{2}-1\right)}{4}\right)-x N_{R} \theta \\
+N\left(m-V_{\gamma}+x N_{R} \theta+\frac{x^{2}\left(N_{R}-k\right)\left(N_{R}-k-1\right)}{2}\right)
\end{array}\right)-N F .
\end{aligned}
$$


This expression is valid for $0 \leq k \leq N_{R}$.

Suppose there exists $k \in\left[1, N_{R}-1\right]$ such that $\Pi(k) \geq \Pi(0)$ and $\Pi(k) \geq \Pi\left(N_{R}\right)$. These two inequalities are equivalent to

$$
\begin{aligned}
V_{\delta}-V_{\gamma} & \geq \frac{x^{2}}{4}\left[2 N\left(2 N_{R}-k-1\right)+3 N_{R} k-3 N_{R}^{2}-k^{2}+1\right] \\
V_{\delta}-V_{\gamma} & \leq \frac{x^{2}}{4}\left(N_{R}-k-1\right)\left(2 N-1-\left(N_{R}-k\right)\right)
\end{aligned}
$$

respectively. For both inequalities to hold requires $2 N_{R}-k \geq 2 N$, which is not possible given $N_{R}<N$ and $k \geq 0$ We have thus shown that selling some (but not all) products from $S_{R}$ in the $M$-mode is a dominated strategy.

The other possible strategy to consider is that in addition to the $N_{R}$ products in $S_{R}$, the intermediary sells $k$ products from $S_{M}$ in the $R$-mode, where $0 \leq k \leq N-N_{R}$. Denote by $S_{0}$ the set of $k$ products from $S_{M}$ which are sold under the $R$-mode. The intermediary chooses marketing activities $a_{i}=\theta+\gamma_{i}+x\left(N_{R}+k-1\right) / 2$ for products $i \in S_{R}$ and $a_{i}=\theta+\gamma_{i}$ for products $i \in S_{0}$ (the latter create no spillovers). Independent suppliers set $a_{i}=\theta+\delta_{i}$ for the remaining products $i \in S_{M} \backslash S_{0}$. The intermediary's profit is therefore

$$
\begin{aligned}
& \Pi(k)=(v-f) \sum_{i \in S_{R}} E\left[m-\left(\frac{x\left(N_{R}+k-1\right)}{2}-\delta_{i}\right)^{2}+x \sum_{j \neq i, j \in S_{R}}\left(\theta+\gamma_{j}+\frac{x\left(N_{R}+k-1\right)}{2}\right)\right] \\
& +(v-f) \sum_{i \in S_{0}} E\left[m-\delta_{i}^{2}+x \sum_{j \in S_{R}}\left(\theta+\gamma_{j}+\frac{x\left(N_{R}+k-1\right)}{2}\right)\right] \\
& +(v-f) \sum_{i \in S_{M} \backslash S_{0}} E\left[m-\gamma_{i}^{2}+x \sum_{j \in S_{R}}\left(\theta+\gamma_{j}+\frac{x\left(N_{R}+k-1\right)}{2}\right)\right]-N F \\
& =(v-f)\left(\begin{array}{c}
\left(N_{R}+k\right)\left(V_{\gamma}-V_{\delta}\right)+N\left(m-V_{\gamma}\right)+x \theta N_{R}(N-1) \\
+\frac{x^{2}}{4} N_{R}\left(N_{R}+k-1\right)\left(2 N-N_{R}-k-1\right)
\end{array}\right)-N F .
\end{aligned}
$$

We therefore have

$$
\Pi(k) \geq \Pi(k-1) \Longleftrightarrow V_{\delta}-V_{\gamma}<\frac{x^{2}}{4} N_{R}\left(2\left(N-N_{R}\right)+1-2 k\right) .
$$

Note the right hand side of the last inequality is strictly decreasing in $k$. Thus, there is a unique value of $k^{*}$ that maximizes $\Pi(k)$ over $k \in\left[0, N-N_{R}\right]$. In particular, $k^{*}=N-N_{R}$ (i.e. the $R$-mode) is optimal if $V_{\delta}-V_{\gamma} \leq \frac{x^{2}}{4} N_{R}$. On the other hand, $k^{*}=0$ (i.e. only the products in $S_{R}$ are sold in the $R$-mode) is optimal if

$$
V_{\delta}-V_{\gamma} \geq \frac{x^{2}}{4} N_{R}\left[2\left(N-N_{R}\right)-1\right]
$$

Otherwise, $k^{*}$ satisfies the bounds in (18).

The intermediary's profit is then $\max \left\{\Pi\left(k^{*}\right), \Pi_{M}\right\}$, where $\Pi_{M}$ is the profit obtained with the $M$-mode

$$
\Pi_{M}=(v-f)\left[N\left(m-V_{\gamma}\right)+x \theta N_{R}(N-1)\right]-N F .
$$


The $M$-mode yields higher profits than $\Pi(0)$ if and only if

$$
V_{\delta}-V_{\gamma} \geq \frac{x^{2}}{4}\left(1-N_{R}^{2}+2 N\left(N_{R}-1\right)\right) .
$$

Since $N_{R}^{2}+N_{R} \geq 2 N-1$, we have that (22) implies (21). Thus, if $\Pi_{M}>\Pi(0)$ then the $M$-mode will be chosen. If on the other hand $\Pi_{M} \leq \Pi(0)$ then the optimal solution is given by the $k^{*}$ characterized above.

\section{Proof of Proposition 10}

Compare intermediary profits in (19) with $n_{R}$ products in the $R$-mode versus $n_{R}-1$ products in the $R$-mode. Offering $n_{R}$ products in the $R$-mode is better than offering $n_{R}-1$ products if and only if $2 \alpha\left(N-n_{R}\right)+V_{\gamma}>V_{\delta}$. Starting from $n_{R}=1$, the left-hand side of the inequality is strictly decreasing in $n_{R}$, so there will be a unique optimal value of $n_{R}$ for all parameter values. The intermediary's profit is higher with $n_{R}=0$ than with $n_{R}=1$ if and only if $V_{\delta}>V_{\gamma}+2 \alpha(N-1)$, which implies the optimal $n_{R}$ is 0 . Likewise, the intermediary's profit is higher with $n_{R}=N$ than with $n_{R}=N-1$ if and only if $V_{\delta}<V_{\gamma}$, which implies the optimal $n_{R}$ is $N$. The optimal model is therefore an interior hybrid whenever $V_{\gamma}<V_{\delta}<V_{\gamma}+2 \alpha(N-1)$. In this case, the optimal number $n_{R}^{*}$ satisfies $2 \alpha\left(N-n_{R}^{*}\right)+V_{\gamma}>V_{\delta}$ and $2 \alpha\left(N-\left(n_{R}^{*}+1\right)\right)+V_{\gamma}<V_{\delta}$, so its bounds are determined in (20).

\section{B Supplementary Appendix}

This appendix provides the formal analysis for the various generalizations of Section 5 . It shows the robustness of our benchmark tradeoffs in each case.

\section{B.1 Costly marketing activities}

Let us first analyze the benchmark model with the alternative formulation of marketing activities introduced in Section 5.1 of the paper. We assume throughout that (1) is adjusted to ensure $M$ can obtain a positive profit in each case, as we did for the different settings in Section 3.

The optimal level of marketing activities chosen by a reseller for each product is

$$
a_{i}^{R}=\frac{(v-f)\left(\theta+\gamma_{i}\right)}{\kappa},
$$

implying the reseller's profit given all products are offered is

$$
\Pi_{R}=N\left((v-f) m+\frac{(v-f)^{2}\left(\theta^{2}+V_{\gamma}\right)}{\kappa}-F\right) .
$$

In the case of a marketplace, the result of profit maximization by supplier $i$ is

$$
a_{i}^{M}=\frac{(v-f)\left(\theta+\delta_{i}\right)}{\kappa},
$$

implying a marketplace which can extract full profits from each supplier obtains

$$
\Pi_{M}=N\left((v-f) m+\frac{(v-f)^{2}\left(\theta^{2}+V_{\delta}\right)}{\kappa}-F\right) .
$$


Comparing $\Pi_{M}$ with $\Pi_{R}$, the $M$-mode is preferred to the $R$-mode if and only if $V_{\delta} \geq V_{\gamma}$, i.e. exactly the same result as in Proposition 1 in the main text.

We next introduce the possibility of spillovers, cost differences and network effects.

\section{B.1.1 Cross-product spillovers}

Suppose there are spillovers in demand which follow the same linear specification given in Section 3.1. As in Section 3.1, we assume favorable expectations if $x$ is positive. The reseller's expected profit at stage 2 is

$$
\Pi_{R}(n)=\max _{a_{1}, a_{2}, . ., a_{n}}\left\{\sum_{i=1}^{n} E_{R}\left[(v-f)\left(m+2\left(\theta+\gamma_{i}+\delta_{i}\right) a_{i}+x \sum_{j \neq i} a_{j}\right)-\kappa a_{i}^{2}\right]-n F\right\} .
$$

This implies

$$
a_{i}^{R}=\frac{(v-f)\left(2\left(\theta+\gamma_{i}\right)+x(n-1)\right)}{2 \kappa},
$$

and leads to

$$
\Pi_{R}=N\left((v-f) m+\frac{(v-f)^{2}}{\kappa}\left(\theta^{2}+V_{\gamma}+x \theta(N-1)+\frac{(N-1)^{2} x^{2}}{4}\right)-F\right) .
$$

For the $M$-mode, supplier $i$ 's expected profit at stage 2 is

$$
\pi_{i}=E_{i}\left[(v-f)\left(m+2\left(\theta+\gamma_{i}+\delta_{i}\right) a_{i}+x \sum_{j \neq i} a_{j}\right)-\kappa a_{i}^{2}\right]-F
$$

This implies

$$
a_{i}^{M}=\frac{(v-f)\left(\theta+\delta_{i}\right)}{\kappa}
$$

and leads to

$$
\Pi_{M}=N\left((v-f) m+\frac{(v-f)^{2}}{\kappa}\left(\theta^{2}+V_{\delta}+x \theta(N-1)\right)-F\right) .
$$

Comparing $\Pi_{M}$ with $\Pi_{R}$, the $M$-mode is preferred to the $R$-mode if and only if $V_{\delta}>V_{\gamma}+\frac{(N-1)^{2} x^{2}}{4}$, i.e. exactly the same result as in Proposition 2 in the main text.

With costly marketing activities and cross-product spillovers, the marketplace may do strictly better by charging variable fees to suppliers instead of just fixed fees (note that without spillovers variable fees are useless). This is because, unlike in our benchmark specification in the main text, the level of costly marketing activity chosen depends on the margin obtained by the supplier. By reducing (increasing) the margin through a variable fee (per unit subsidy), the marketplace can ensure negative (positive) spillovers are internalized, at least partially. Accordingly, suppose the marketplace can monitor supplier sales and charge variable fee $p$ in addition to fixed fee $P$. Supplier $i$ profits at stage 2 are now:

$$
\pi_{i}=E_{i}\left[(v-p-f)\left(m+2\left(\theta+\gamma_{i}+\delta_{i}\right) a_{i}+x \sum_{j \neq i} a_{j}\right)-\kappa a_{i}^{2}\right]
$$

so that

$$
a_{i}^{M}=\frac{(v-p-f)\left(\theta+\delta_{i}\right)}{\kappa} .
$$


With favorable expectations, the marketplace can set:

$$
P=(v-p-f) m+\frac{(v-p-f)^{2}\left(\theta^{2}+V_{\delta}+\theta(N-1) x\right)}{\kappa}-F
$$

in order to extract the entire expected supplier profit from the perspective of stage 1 .

The marketplace's expected profits are then:

$$
N\left(P+p\left(m+\frac{(v-p-f)\left(2\left(\theta^{2}+V_{\delta}\right)+\theta(N-1) x\right)}{\kappa}\right)\right) .
$$

Optimizing with respect to $p$ implies:

$$
p^{*}=-\frac{(v-f) \theta(N-1) x}{2\left(\theta^{2}+V_{\delta}\right)}
$$

Note the variable fee is positive when the spillover is negative and negative when the spillover is positive. The resulting marketplace profits are

$$
N\left((v-f) m+\frac{(v-f)^{2}\left(2\left(\theta^{2}+V_{\delta}\right)+\theta(N-1) x\right)^{2}}{4 \kappa\left(\theta^{2}+V_{\delta}\right)}-F\right) .
$$

Comparing with the reseller's profits, we obtain that the $M$-mode is preferred if and only if:

$$
\left[\theta^{2}+V_{\delta}-\frac{(N-1)^{2} x^{2}}{4}\right] \frac{V_{\delta}}{V_{\delta}+\theta^{2}}>V_{\gamma} .
$$

The left-hand side is increasing in $V_{\delta}$ and $\theta^{2}$ and decreasing in $x^{2}$, so the qualitative effects of local information $\left(V_{\delta}\right.$ and $\left.V_{\gamma}\right)$ and spillovers $\left(x^{2}\right)$ are the same as before. The condition above can also be written

$$
V_{\delta}>V_{\gamma}+\frac{V_{\delta}}{V_{\delta}+\theta^{2}} \frac{(N-1)^{2} x^{2}}{4}
$$

which makes it clear that allowing the marketplace to charge variable fees shifts the tradeoff in its favor (as expected).

\section{B.1.2 Cost differences}

Using the profit expressions without spillovers above but allowing the costs $f$ and $F$ to vary by mode, it is easily verified that the $M$-mode is preferred to the $R$-mode if and only if:

$$
V_{\delta} \geq V_{\gamma}+\frac{\kappa}{\left(v-f_{M}\right)^{2}}\left(m\left(f_{M}-f_{R}\right)+F_{M}-F_{R}\right)+\left(\frac{\left(v-f_{R}\right)^{2}}{\left(v-f_{M}\right)^{2}}-1\right)\left(\theta^{2}+V_{\gamma}\right) .
$$

This condition is similar to that in Proposition 3. The interpretation provided in Proposition 3 and its discussion still hold. 


\section{B.1.3 Unfavorable expectations}

The reseller's expected profit is still given by expression (23) above (baseline case without spillovers). With unfavorable expectations, the maximum profit that the marketplace can extract from each supplier is equal to

$$
(v-f) m(1)+\frac{(v-f)^{2}}{\kappa}\left(\theta^{2}+V_{\delta}\right)-F .
$$

From $N$ suppliers, the marketplace obtains

$$
N\left((v-f) m(1)+\frac{(v-f)^{2}}{\kappa}\left(\theta^{2}+V_{\delta}\right)-F\right) .
$$

Thus, the marketplace is better than reseller if and only if

$$
V_{\delta}>V_{\gamma}+\frac{\kappa}{v-f}(m(N)-m(1)) .
$$

The result is almost identical to that in Proposition 4 except for the additional positive constant term in front of $(m(N)-m(1))$.

Let us now allow the marketplace to charge variable fees $p$ in addition to fixed fees. The maximum fixed fee $P$ that the marketplace can charge is:

$$
(v-p-f) m(1)+\frac{(v-p-f)^{2}}{\kappa}\left(\theta^{2}+V_{\delta}\right)-F
$$

so total marketplace profits are

$$
\begin{aligned}
& N\left((v-p-f) m(1)+\frac{(v-p-f)^{2}}{\kappa}\left(\theta^{2}+V_{\delta}\right)-F\right) \\
& +N p\left(m(N)+\frac{2(v-p-f)^{2}}{\kappa}\left(\theta^{2}+V_{\delta}\right)\right) \\
= & N\left((v-f) m(1)+p(m(N)-m(1))+\frac{\left((v-f)^{2}-p^{2}\right)}{\kappa}\left(\theta^{2}+V_{\delta}\right)-F\right) .
\end{aligned}
$$

Note the tradeoff involved in choosing the optimal variable fee: a higher $p$ helps better overcome unfavorable expectations but it leads to lower (sub-optimal) investments in marketing activities. The optimal choice of $p$ is

$$
p^{*}=\frac{\kappa(m(N)-m(1))}{2\left(\theta^{2}+V_{\delta}\right)} .
$$

To ensure that $p^{*}$ is less than $v-f$, we assume

$$
\kappa(m(N)-m(1))<2\left(\theta^{2}+V_{\delta}\right)(v-f),
$$

i.e. we require that the network effect be not too strong.

The resulting profit for the marketplace is

$$
N\left((v-f) m(1)+\frac{(v-f)^{2}\left(\theta^{2}+V_{\delta}\right)}{\kappa}+\frac{\kappa(m(N)-m(1))^{2}}{4\left(\theta^{2}+V_{\delta}\right)}-F\right) .
$$


Comparing this with the reseller's profit, we obtain that the marketplace is better if and only if

$$
V_{\delta}>V_{\gamma}+\frac{\kappa}{v-f}(m(N)-m(1))-\frac{\kappa^{2}(m(N)-m(1))^{2}}{4(v-f)^{2}\left(\theta^{2}+V_{\delta}\right)} .
$$

Like in the main text, the tradeoff is shifted in favor of the marketplace relative to the tradeoff in (24), i.e. the case with no variable fees. This shift in the tradeoff is captured by the new negative term on the right hand side of the inequality. The effect of local information $\left(V_{\delta}\right.$ and $\left.V_{\gamma}\right)$ is unchanged: the marketplace is more likely to be preferred when $V_{\gamma}$ is smaller and $V_{\delta}$ is larger (the latter is a consequence of assumption 25). Similarly, the effect of the strength of network effects $(m(N)-m(1))$ is the same: given (25), the right hand side of the last inequality above is increasing in $m(N)-m(1)$, so that stronger network effects make the reseller mode more attractive.

\section{B.2 Supplier bargaining power}

Consider first the baseline model. The reseller offers each supplier a wholesale price $w$ so as to extract a share $(1-\beta)$ of the expected joint profits created by the supplier's product (net of the fixed cost $F$ ). Given the optimal choice of marketing activity is unaffected by the wholesale price, the expected profit generated per supplier is still $(v-f)\left(m-V_{\delta}\right)-F .{ }^{12}$ Consequently, the reseller sets $w$ so that its expected profit from supplier $i$ is

$$
(v-f-w)\left(m-V_{\delta}\right)-F=(1-\beta)\left((v-f)\left(m-V_{\delta}\right)-F\right)
$$

implying

$$
w=\frac{\beta}{m-V_{\delta}}\left((v-f)\left(m-V_{\delta}\right)-F\right) .
$$

Applying the same rule for all $N$ suppliers implies the reseller's profit is

$$
\Pi_{R}=N(1-\beta)\left((v-f)\left(m-V_{\delta}\right)-F\right) .
$$

Similarly, the marketplace sets its fixed fee $P$ to suppliers so as to extract a share $(1-\beta)$ of the expected joint profits. Since the supplier's optimal choice of marketing activity does not depend on the fixed participation fee, the expected profit generated per supplier is still $(v-f)\left(m-V_{\gamma}\right)-F$. Consequently, the marketplace sets the fixed participation fee $P$ such that

$$
P=(1-\beta)\left((v-f)\left(m-V_{\gamma}\right)-F\right) .
$$

Collecting this from all $N$ suppliers leads to

$$
\Pi_{M}=N(1-\beta)\left((v-f)\left(m-V_{\gamma}\right)-F\right)
$$

Consequently, the $M$-mode is preferred to the $R$-mode if and only if $V_{\delta}>V_{\gamma}$, the same result as in Proposition 1.

It is easily seen that the analysis above also applies to the cases with spillovers (assuming favorable expectations if spillovers are positive) and with cost differences. Thus, Propositions 2 and 3 remain unchanged. The one setting where things do change is in the scenario with network effects and unfavorable expectations. For

\footnotetext{
${ }^{12}$ In the alternative model of marketing activities considered in Section 5.1, the choice of marketing activity would be affected by the wholesale price paid to suppliers, but this would not change our results since the reseller would do better to set $w=0$ and instead make a fixed payment to each supplier equal to $\beta\left((v-f)\left(m-V_{\delta}\right)-F\right)$.
} 
suppliers to join under unfavorable expectations, we must have

$$
P \leq(v-f)\left(m(1)-V_{\gamma}\right)-F .
$$

Bargaining creates an additional constraint - the expected equilibrium surplus left to each supplier after paying the marketplace fixed fee $P$ must be no less than a fraction $\beta$ of the joint surplus the supplier's presence is expected to create in equilibrium $\left((v-f)\left(m(N)-V_{\gamma}\right)-F\right)$. This constraint can be written

$$
P \leq(1-\beta)\left((v-f)\left(m(N)-V_{\gamma}\right)-F\right) .
$$

Thus, $M$ 's profit is

$$
\Pi_{M}=N \min \left\{(v-f)\left(m(1)-V_{\gamma}\right)-F,(1-\beta)\left((v-f)\left(m(N)-V_{\gamma}\right)-F\right)\right\} .
$$

Let

$$
\beta^{*} \equiv \frac{(v-f)(m(N)-m(1))}{(v-f)\left(m(N)-V_{\gamma}\right)-F} .
$$

Note that (14) ensures $0<\beta^{*}<1$. There are therefore two cases:

- If $\beta \geq \beta^{*}$ then the constraint coming from unfavorable expectations (26) is not binding. Then $M$ can extract its bargaining share of the expected joint profits

$$
\Pi_{M}=N(1-\beta)\left((v-f)\left(m(N)-V_{\gamma}\right)-F\right),
$$

and the benchmark tradeoff of Proposition 1 is restored.

- If $\beta<\beta^{*}$ then the binding constraint comes from unfavorable expectations. $M$ 's profit is

$$
\Pi_{M}=N\left((v-f)\left(m(1)-V_{\gamma}\right)-F\right),
$$

so that the benchmark tradeoff is now shifted in favor of the $R$-mode, exactly as in Proposition 4 .

To conclude, if suppliers' bargaining power is large then unfavorable expectations are no longer an issue since each supplier wants to join even if it expects no other suppliers to join. In this case unfavorable expectations have no effect on the benchmark tradeoff. In particular, if network effects are small (i.e. $m(N)-m(1)$ is small) then even a small amount of supplier bargaining power can restore the benchmark results. If on the other hand suppliers do not have much bargaining power, then unfavorable expectations have the same effect as before they make the $R$-mode relatively more attractive.

Suppose now the marketplace can also charge variable fees $p$. The analysis is similar. Unfavorable expectations require

$$
P \leq(v-p-f)\left(m(1)-V_{\gamma}\right)-F
$$

while Nash bargaining requires

$$
P+p\left(m(N)-V_{\gamma}\right) \leq(1-\beta)\left((v-f)\left(m(N)-V_{\gamma}\right)-F\right) .
$$

Again there are two cases. Suppose first that in equilibrium (i.e. at profit-maximizing $p$ and $P$ ) constraint (27) is binding. Then $M$ 's expected profit is

$$
N\left((v-f)\left(m(1)-V_{\gamma}\right)+p(m(N)-m(1))-F\right),
$$


which is increasing in $p$. Thus, the marketplace wants to set $p$ as high as possible provided $P \geq 0$. This implies

$$
p^{*}=v-f-\frac{F}{m(1)-V_{\gamma}} .
$$

Assumption (14) ensures $0<p^{*}<v-f$. The corresponding profit for $M$ is therefore

$$
N\left((v-f)\left(m(N)-V_{\gamma}\right)-F \frac{m(N)-V_{\gamma}}{m(1)-V_{\gamma}}\right) .
$$

This compares to the profit $N(1-\beta)\left((v-f)\left(m(N)-V_{\gamma}\right)-F\right)$ in case the constraint (28) is binding.

Thus, $M$ 's profit is

$$
\Pi_{M}=N \min \left\{(v-f)\left(m(N)-V_{\gamma}\right)-F \frac{m(N)-V_{\gamma}}{m(1)-V_{\gamma}},(1-\beta)\left((v-f)\left(m(N)-V_{\gamma}\right)-F\right)\right\} .
$$

Let

$$
\beta^{* *} \equiv \frac{(m(N)-m(1)) F}{\left(m(1)-V_{\gamma}\right)\left((v-f)\left(m(N)-V_{\gamma}\right)-F\right)} .
$$

Note that (14) ensures $0<\beta^{* *}<1$. Again, there are two cases:

- If $\beta \geq \beta^{* *}$ then the constraint coming from unfavorable expectations (27) is not binding. Then $M$ can extract its bargaining share of the expected joint profits

$$
\Pi_{M}=N(1-\beta)\left((v-f)\left(m-V_{\gamma}\right)-F\right),
$$

and the benchmark tradeoff of Proposition 1 is restored.

- If $\beta<\beta^{* *}$ then the binding constraint comes from unfavorable expectations. $M$ 's profit is

$$
\Pi_{M}=N\left((v-f)\left(m(N)-V_{\gamma}\right)-F \frac{m(N)-V_{\gamma}}{m(1)-V_{\gamma}}\right),
$$

so that the benchmark tradeoff is now shifted in favor of the $R$-mode, exactly as in Proposition 5 .

Finally, note that (14) implies $\beta^{* *} \leq \beta^{*}$. This means that the threshold for supplier bargaining power above which unfavorable expectations do not matter is lowered when the marketplace can charge variable fees. In other words, variable fees make unfavorable expectations less likely to constrain the marketplace.

\section{B.3 Downward-sloping supplier demand}

Suppose suppliers are heterogeneous in $m$, i.e. $m$ is distributed on $\left[m_{L}, m_{H}\right]$ with CDF $G($.$) and corresponding$ density $g($.$) , and that the intermediary does not observe each individual supplier's m_{i}$. We also assume:

$$
(v-f)\left(m_{L}-\max \left(V_{\gamma}, V_{\delta}\right)\right)>F
$$

so that all products are profitable. Given unobserved heterogeneity in $m$, it is natural to allow both $M$ and $R$ to charge fixed and variable fees. Specifically, $M$ charges the fixed fee $P_{M}$ and the variable fee $p$, while the reseller charges the fixed fee $P_{R}$ and offers suppliers a bid $b$ per product unit it buys from them.

Consider first the $M$-mode. A supplier with $m_{i}=m$ participates in the marketplace if and only if

$$
m \geq \widehat{m} \equiv \frac{P_{M}+F}{v-f-p}+V_{\gamma} .
$$


Thus, $M$ 's profit is

$$
\begin{aligned}
& \max _{P_{M}, p}\left\{\left(P_{M}+p E(m \geq \widehat{m})\right)(1-G(\widehat{m}))\right\} \\
= & \max _{\widehat{m}, p}\left\{\left((v-f)\left(m-V_{\gamma}\right)+p(E(m \geq \widehat{m})-m)-F\right)(1-G(\widehat{m}))\right\} .
\end{aligned}
$$

Clearly the last expression is increasing in $p$ so the optimal $p$ is $v-f-\varepsilon$, with $\varepsilon$ being arbitrarily small. We obtain

$$
\Pi_{M}=\max _{\widehat{m}}\left\{\left((v-f)\left(E(m \geq \widehat{m})-V_{\gamma}\right)-F\right)(1-G(\widehat{m}))\right\} .
$$

Similarly, $R$ 's profit is

$$
\max _{P_{R}, b}\left\{\left(P_{R}+(v-f-b)\left(E(m \geq \widehat{m})-V_{\delta}\right)-F\right)(1-G(\widehat{m}))\right\}
$$

where

$$
b\left(\widehat{m}-V_{\delta}\right)-P_{R}=0
$$

so that $R$ 's profit can be rewritten as

$$
\max _{\widehat{m}, b}\left\{\left(b\left(\widehat{m}-V_{\delta}\right)+(v-f-b)\left(E(m \geq \widehat{m})-V_{\delta}\right)-F\right)(1-G(\widehat{m}))\right\} .
$$

The last expression is decreasing in $b$ so the optimal $b$ is equal to $\varepsilon$, where $\varepsilon$ is arbitrarily close to zero. We obtain

$$
\Pi_{R}=\max _{\widehat{m}}\left\{\left((v-f)\left(E(m \geq \widehat{m})-V_{\delta}\right)-F\right)(1-G(\widehat{m}))\right\} .
$$

Comparing the two profits (29) and (30), it is clear that $M$ is preferred to $R$ if and only if $V_{\delta}>V_{\gamma}$, the same condition as in our benchmark model. It is also straightforward to prove that in the current setting with no cost differences, an interior hybrid mode is never optimal. This feature also parallels the benchmark model.

\section{B.4 Buyer surplus and affiliation}

Assume buyers incur heterogeneous opportunity costs $c$ when joining the intermediary $(M$ or $R$ ), where $c$ is distributed with the CDF $D($.$) . Furthermore, we replace the pricing mechanism in the main text with Nash$ bargaining. Specifically, we assume that after joining the intermediary, each buyer engages in Nash bargaining with the owner of the product $i$ she is interested in. When supplier $i$ sells directly to buyers (in the $M$-mode), supplier $i$ 's bargaining power is $\alpha_{M}$ so that the supplier's and buyer's payoffs from the interaction are

$$
\pi_{M}=\alpha_{M}\left(v-f_{M}\right) \text { and } s_{M}=\left(1-\alpha_{M}\right)\left(v-f_{M}\right) .
$$

When $R$ sells to buyers, its bargaining power is $\alpha_{R} \geq \alpha_{M}$. This captures the fact that $R$ aggregates the bargaining power of all suppliers. In this case, $R$ 's and the buyer's payoffs from one product transaction are

$$
\pi_{R}=\alpha_{R}\left(v-f_{R}\right) \text { and } s_{R}=\left(1-\alpha_{R}\right)\left(v-f_{R}\right)
$$

Since it is assumed $f_{M} \geq f_{R}$ and $\alpha_{M} \leq \alpha_{R}$, we always have $\pi_{R} \geq \pi_{M}$. On the other hand, it is possible that $s_{M} \geq s_{R}$ (i.e. buyers may derive more surplus from their interactions with individual suppliers on $M$ because they have more relative bargaining power, which may compensate for the higher cost). We also allow $M$ and $R$ to have different fixed costs, $F_{R}$ and $F_{M}$ respectively, as in Section 3.2.

Finally, to keep things simple, we assume the intermediary cannot charge any fixed fees to buyers for 
affiliation (neither as $M$ nor as $R$ ). If this was possible, $M$ may be able to partially offset the inferior bargaining power of its suppliers relative to $R$.

The rest of the model is unchanged. Assuming that each buyer is interested in one product only, demand for product $i$ is now

$$
\begin{aligned}
& {\left[m-\left(a_{i}-a_{i}^{*}\right)^{2}\right] D\left(s_{M}\right) \text { if the intermediary behaves as a marketplace }} \\
& {\left[m-\left(a_{i}-a_{i}^{*}\right)^{2}\right] D\left(s_{R}\right) \text { if the intermediary behaves as a reseller. }}
\end{aligned}
$$

These expressions suggests that the $M$-mode now has an additional advantage whenever $s_{M}>s_{R}$ since it creates more buyer demand as buyers retain more surplus.

With these demand expressions, it is straightforward to derive the profits of $M$ and $R$ (the analysis is almost identical to the one in Section 3.2), obtaining

$$
\begin{aligned}
\Pi_{R}(N) & =N\left(\pi_{R}\left(m-V_{\delta}\right) D\left(s_{R}\right)-F_{R}\right) \\
\Pi_{M}(N) & =N\left(\pi_{M}\left(m-V_{\gamma}\right) D\left(s_{M}\right)-F_{M}\right) .
\end{aligned}
$$

Taking the difference and re-arranging terms, we obtain that the $M$-mode is preferred to the $R$-mode if and only if

$$
\pi_{R} D\left(s_{R}\right) V_{\delta}>\pi_{M} D\left(s_{M}\right) V_{\gamma}+m\left(\pi_{R} D\left(s_{R}\right)-\pi_{M} D\left(s_{M}\right)\right)-\left(F_{R}-F_{M}\right)
$$

which is similar to the tradeoff including cost differences expressed in (13). The only difference is that $\left(v-f_{M}\right)$ and $\left(v-f_{R}\right)$ have been replaced by the more general terms $\pi_{M} D\left(s_{M}\right)$ and $\pi_{R} D\left(s_{R}\right)$, respectively.

If we eliminate cost differences by setting $f_{R}=f_{M}=f$ and $F_{R}=F_{M}=F$, then, since $m>V_{\gamma}$ by assumption, the tradeoff is shifted in favor of $M$ relative to the benchmark tradeoff in Proposition 1 if and only if:

$$
\pi_{M} D\left(s_{M}\right)>\pi_{R} D\left(s_{R}\right)
$$

i.e. if and only if

$$
\alpha_{M}(v-f) D\left(\left(1-\alpha_{M}\right)(v-f)\right)>\alpha_{R}(v-f) D\left(\left(1-\alpha_{R}\right)(v-f)\right) .
$$

This represents a simple tradeoff: the $R$-mode allows the intermediary to extract more rents out of the buyers who join, but for this exact reason the $M$-mode may attract a larger number of buyers.

\section{B.5 Price as the non-contractible decision variable}

Suppose there are $N$ products with demand for product $i$ given by

$$
m+\delta_{i}+\gamma_{i}-p_{i}+\frac{x}{N-1} \sum_{j \neq i} p_{j}
$$

where $-1<x<1$. The demand shock $\delta_{i}$ is the local information of supplier $i$ and the demand shock $\gamma_{i}$ is the local information of the intermediary. We assume $\delta_{i}$ and $\gamma_{i}$ are i.i.d. draws from independent distributions, with expected values and variances $V_{\delta}$ and $V_{\gamma}$, respectively. All marginal and fixed costs are set to zero for simplicity, and so there are no cost differences between the two modes, as in Section 3.

$R$ does not observe $\left(\delta_{1}, \ldots, \delta_{N}\right)$ but can set $\left(p_{1}, \ldots, p_{N}\right)$ to account for demand spillovers and its local infor- 
mation $\left(\gamma_{1}, \ldots, \gamma_{N}\right)$. It therefore solves

$$
\max _{p_{1}, \ldots, p_{N}}\left\{\sum_{i=1}^{N} p_{i}\left(m+\gamma_{i}-p_{i}+\frac{x}{N-1} \sum_{j \neq i} p_{j}\right)\right\} .
$$

The first-order condition in $p_{i}$ yields

$$
p_{i}^{*}=\frac{m+\gamma_{i}}{2}+\frac{x}{N-1} \sum_{j \neq i} p_{j}^{*}
$$

Taking the sum of these conditions over $i=1, . ., N$, and noting $\sum_{i=1}^{N} \sum_{j \neq i} p_{j}^{*}=(N-1) \sum_{i=1}^{N} p_{i}^{*}$ we obtain

$$
\sum_{i=1}^{N} p_{i}^{*}=\frac{N m}{2(1-x)}+\frac{\sum_{i=1}^{N} \gamma_{i}}{2(1-x)} .
$$

Subtracting (31) from (32) we can obtain $\sum_{j \neq i} p_{j}^{*}$, and substituting this into (31) we obtain

$$
p_{i}^{*}=\frac{m}{2(1-x)}+\frac{a}{2} \gamma_{i}+\frac{b}{2} \sum_{j \neq i} \gamma_{j}
$$

where the parameters $a$ and $b$ are defined by

$$
\begin{aligned}
a & \equiv \frac{(N-1)-(N-2) x}{(N-1)-(N-2) x-x^{2}} \\
b & =\frac{x}{(N-1)-(N-2) x-x^{2}} .
\end{aligned}
$$

From the perspective of the initial stage

$$
\Pi_{R}=\sum_{i=1}^{N}\left[E\left[p_{i}^{*} m\right]+E\left[p_{i}^{*} \gamma_{i}\right]-E\left[\left(p_{i}^{*}\right)^{2}\right]+\frac{x}{N-1} \sum_{j \neq i} E\left[p_{i}^{*} p_{j}^{*}\right]\right] .
$$

We have

$$
\begin{aligned}
E\left[p_{i}^{*} m\right] & =\frac{m^{2}}{2(1-x)} ; E\left[p_{i}^{*} \gamma_{i}\right]=\frac{a}{2} V_{\gamma} \\
E\left[\left(p_{i}^{*}\right)^{2}\right] & =\frac{m^{2}}{4(1-x)^{2}}+\frac{a^{2}+(N-1) b^{2}}{4} V_{\gamma} \\
E\left[p_{i}^{*} p_{j}^{*}\right] & =\frac{m^{2}}{4(1-x)^{2}}+\frac{2 a b+(N-2) b^{2}}{4} V_{\gamma} .
\end{aligned}
$$

Plugging these expressions in $\Pi_{R}$ above and using the definitions of $a$ and $b$, we finally obtain

$$
\Pi_{R}=N\left(\frac{m^{2}}{4(1-x)}+\frac{(N-1-x(N-2))}{4(1-x)(N-1+x)} V_{\gamma}\right) .
$$

Consider now $M$ 's problem. It sets a participation fee that extracts the entire expected surplus from each 
supplier. Supplier $i$ sets $p_{i}$ to maximize

$$
\pi_{i}=p_{i}\left(m+\delta_{i}-p_{i}+\frac{x}{N-1} \sum_{j \neq i} E_{i}\left[p_{j}\right]\right)
$$

where $E_{i}\left[p_{j}\right]$ denotes the expectation of $p_{j}$ from the perspective of supplier $i$. This implies

$$
p_{i}^{*}=\frac{1}{2} \delta_{i}+\frac{1}{2}\left(m+\frac{x}{N-1} \sum_{j \neq i} E_{i}\left[p_{j}^{*}\right]\right) .
$$

Taking expectations of both sides (and using that $E_{i}\left(\delta_{j}\right)=0$ ) yields

$$
E_{i}\left[p_{j}^{*}\right]=\frac{m}{2-x} .
$$

Substituting (34) into (33), we obtain

$$
p_{i}^{*}=\frac{1}{2} \delta_{i}+\frac{m}{2-x} .
$$

Substituting $p_{i}^{*}$ into $\pi_{i}$ and taking expectations, we obtain

$$
\pi_{i}=\frac{V_{\delta}}{4}+\frac{m^{2}}{(2-x)^{2}}
$$

Thus, summing over all $N$ suppliers implies

$$
\Pi_{M}=N\left(\frac{V_{\delta}}{4}+\frac{m^{2}}{(2-x)^{2}}\right) .
$$

We can now compare the resulting profits under the two intermediation modes by taking the difference. We obtain

$$
\Pi_{M}-\Pi_{R}=N\left(\frac{V_{\delta}}{4}-\frac{(N-1-x(N-2))}{4(1-x)(N-1+x)} V_{\gamma}-\frac{m^{2} x^{2}}{4(1-x)(2-x)^{2}}\right) .
$$

This difference is clearly increasing in $V_{\delta}$ and decreasing in $V_{\gamma}$, so the $M$-mode is preferred when $V_{\delta}$ is sufficiently high, whereas the $R$-mode is preferred when $V_{\gamma}$ is sufficiently high. If there are no spillovers so $x=0$, then $\Pi_{M}-\Pi_{R}=N\left(V_{\delta}-V_{\gamma}\right) / 4$, so the tradeoff is identical to the one given in Proposition 1. Moreover, it is easily verified that $\Pi_{M}-\Pi_{R}$ is decreasing in $|x|$. Thus, the presence of spillovers unambiguously shifts the tradeoff in favor of $R$, regardless of their sign. This result corroborates the one obtained in Proposition 2. 